\title{
UNDERSTANDING BARRIERS TO ACCESSING MENTAL HEALTH SERVICES FOR NEWCOMERS TO CANADA USING PETERBOROUGH, ONTARIO, AS AN \\ ILLUSTRATIVE EXAMPLE
}

\author{
By
}

Nurun Layla Chowdhury, BSc Hon, Memorial University of Newfoundland, 2012

In partial fulfillment of the requirements for the degree of

\author{
Master of Arts \\ In the Program of \\ Immigration and Settlement Studies
}

Toronto, Ontario, Canada, 2017

CNurun Layla Chowdhury 2017 


\section{AUTHOR'S DECLARATION FOR ELECTRONIC SUBMISSION OF A MAJOR RESEARCH PAPER (MRP)}

I hereby declare that I am the sole author of this Major Research Paper. This is a true copy of the MRP, including any required final revisions, as accepted by my examiners.

I authorize Ryerson University to lend this MRP to other institutions or individuals for the purpose of scholarly research.

I further authorize Ryerson University to reproduce this MRP by photocopying or by other means, in total or in part, at the request of other institutions or individuals for the purpose of scholarly research.

I understand that my MRP may be made electronically available to the public.

Nurun Layla Chowdhury 
Understanding Barriers To Accessing Mental Health Services For Newcomers To Canada Using Peterborough, Ontario, As An Illustrative Example

\author{
Nurun Layla Chowdhury \\ Master of Arts 2017 \\ Immigration and Settlement Studies \\ Ryerson University
}

\begin{abstract}
The quality of an individual's mental health has a significant impact on their quality of life, as well as on the cost to society. Regular access to mental health services can help mitigate the risk factors of developing mental illnesses. This paper examines barriers to accessing mental health services, using the community of Peterborough, Ontario, as an example. Social, economic, and cultural barriers impact help-seeking amongst immigrants, putting them at a higher risk of developing mental disorders. The social determinants of mental health can be useful when developing policies aimed at improving utilization of mental healthcare services. Policy makers need to first focus on collecting accurate information on the population, and then developing targeted solutions to eliminate barriers such as language and employment that prevent helpseeking in immigrants.
\end{abstract}

Keywords: Immigrant, ethnic minority, mental health, access, barrier, utilization, cultural competence, cultural sensitivity, Canada, Ontario, Peterborough, healthcare policy, social determinants, stigma, and language barrier. 


\section{ACKNOWLEDGEMENTS}

The completion of this MRP would not have been possible without the unwavering support, encouragement, and patience of my supervisor, Dr. Francis Hare. He was my inspiration when I fumbled and helped me find the true purpose of my paper. I will forever be grateful. Thank you.

I would like express my gratitude to the entire department of Immigration and Settlement Studies at Ryerson, which provided me with the avenue to pursue my dreams. I want to thank all the professors of the program who opened my eyes to the issues of immigrants in Canada, as well as my classmates, who constantly supported and challenged me to further develop myself.

I would also like to thank my partner in life, Omar Patwari, who has been my sounding board of ideas, good or bad. I also want to thank my parents, who have always believed in me and truly made me what I am today. I want to send a special thanks to all my friends who provided countless hours of discussions, edits, and encouragement to get my MRP completed. Thank you Amanda, Brankica, Dana, Erin and so many others.

Finally, I want to thank God for allowing me to overcome the many obstacles in my life and letting me complete this major milestone. 


\section{TABLE OF CONTENTS}

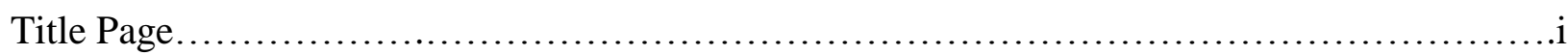

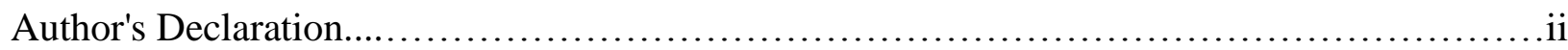

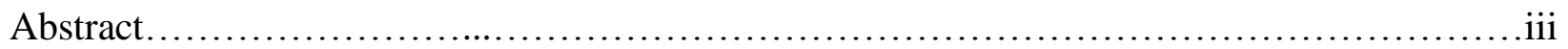

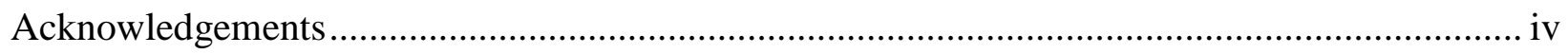

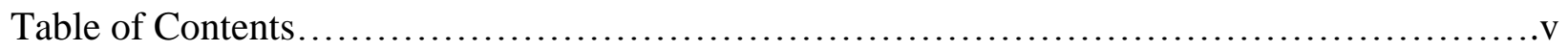

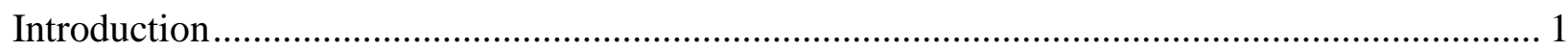

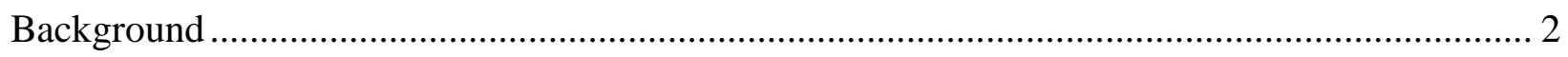

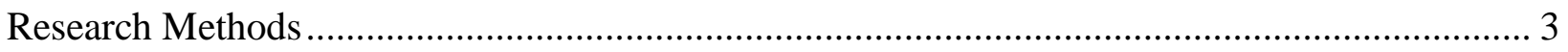

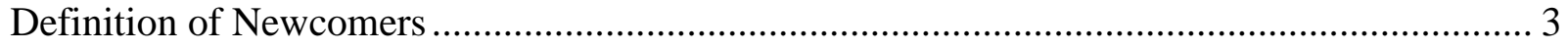

Parameters of Research ......................................................................................... 4

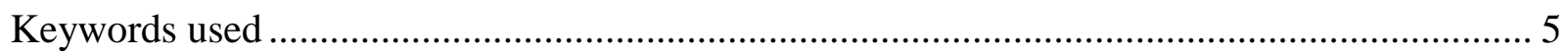

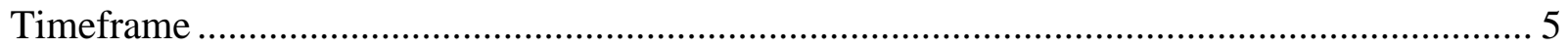

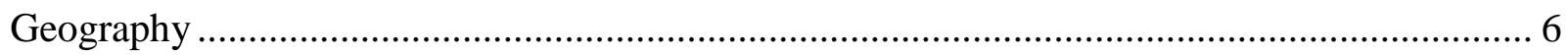

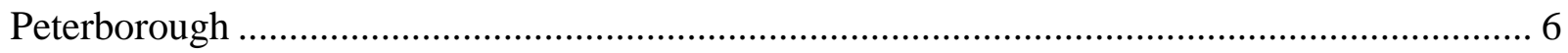

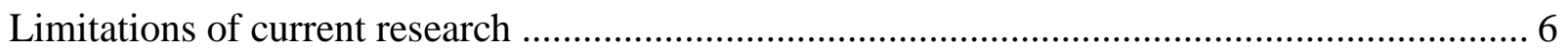

Importance of Mental Well-being/ Cost of mental illness ............................................... 7

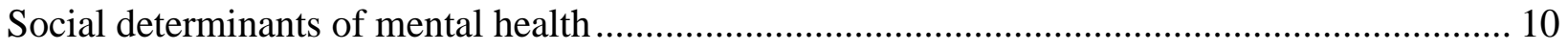

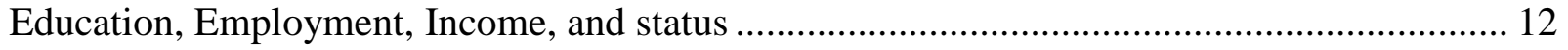


Social support and social exclusion

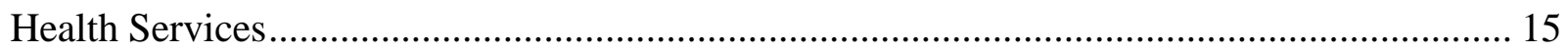

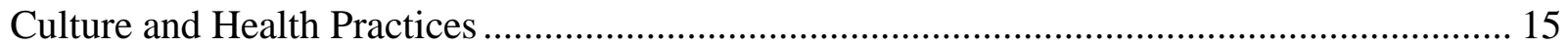

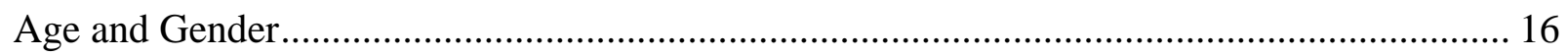

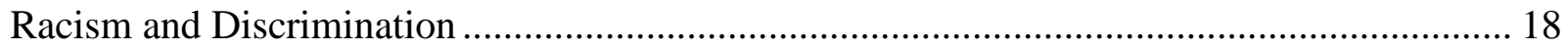

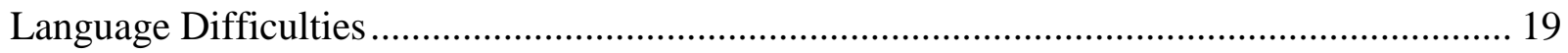

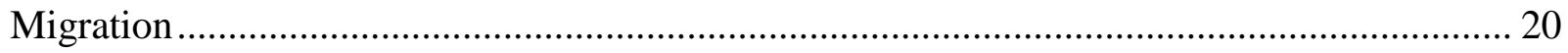

Mental health service utilization............................................................................... 20

Discussion of barriers to service utilization.................................................................. 24

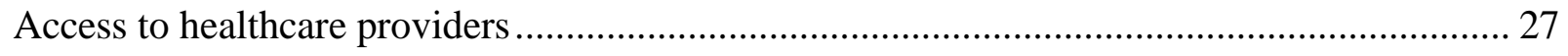

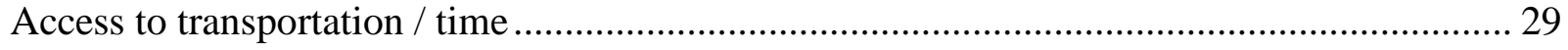

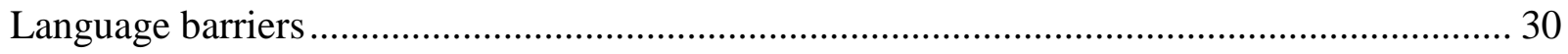

Lack of cultural competency training for service providers ........................................... 32

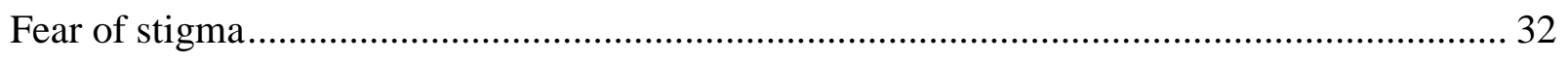

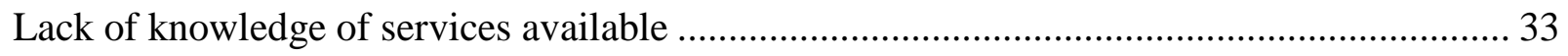

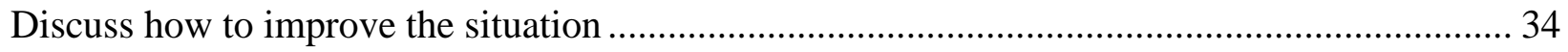

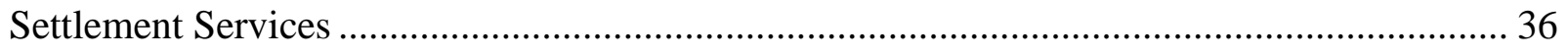

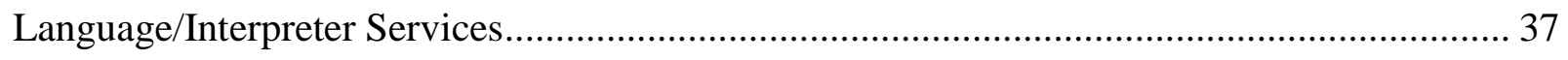

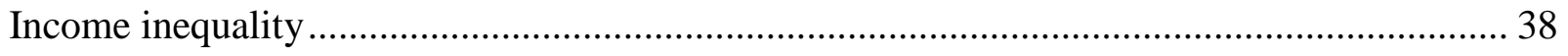

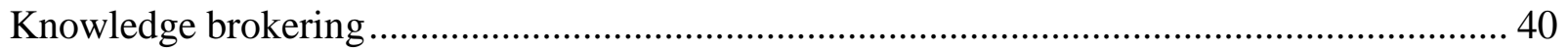


Continuity \& Community

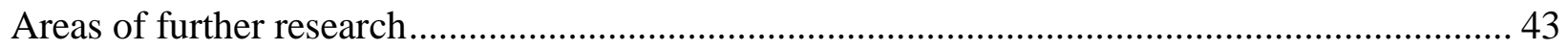

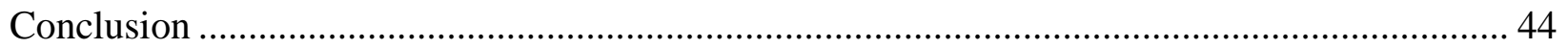

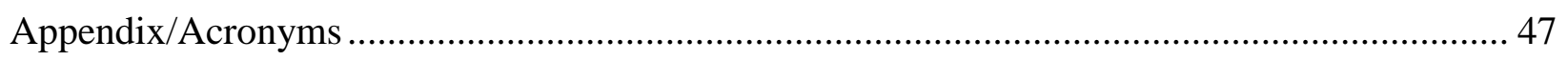

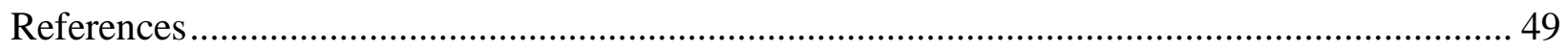




\section{INTRODUCTION}

When was the last time you walked into your family doctor's office and got asked about your mental health? When someone in Canada looks for mental health services in their communities, different options are available to them. They can go to their family doctor (if they have one), to a community support centre that offers counselling or referral services, or see someone in private practice by paying out-of-pocket or through their medical insurance coverage. For many immigrants, however, their first line of contact for such services may start at the local immigrant serving organization, if one exists. For Peterborough, Ontario, such an organization is the New Canadian Centre (NCC). The NCC is the only immigrant-specific support centre in the area, and they provide services to newcomers in the Peterborough and Northumberland regions.

I am an immigrant to Canada. While crossing the many stages in my journey towards obtaining Canadian citizenship, I encountered numerous barriers and witnessed other immigrants have similar experiences. The common outcome was always the same: additional stress and mental turmoil. Although many support services for immigration-related logistics exist in major urban centres, this is not entirely the case for smaller regions in Canada that see lower numbers of immigrants. Additionally, mental health is one topic across Canada that lacks the attention it deserves, due, in part, to limited funding options. The research topic of my Major Research Paper (MRP) looks at barriers to accessing mental health resources for newcomers, using Peterborough as an illustrative example. Newcomers can be immigrants, temporary residents, permanent residents, or refugees who have migrated to Peterborough from across the world. Even if the official immigration designations vary, the primary mental health barriers faced by newcomers can be quite similar. Because of this, terminologies have been used interchangeably 
throughout this paper. In this MRP, I would first like to provide the readers with some relevant information on the research methods used to identify issues related to immigrant mental health. Next, there will be an examination of the importance of mental well-being for the population as a whole, followed by a section outlining a theory of the utilization of mental health services. The subsequent section will establish a discussion of the barriers to service utilization and notions on eliminating barriers. Throughout the paper, specific examples from Peterborough and its immigrant population will be used for clarification. The conclusion will include the major ideas that emerged from different data reviews and a discussion of other considerations in this field.

\section{BACKGROUND}

The Canada Health Act of 1984 says that the "primary objective of Canadian health care policy is to protect, promote, and restore the physical and mental well-being of residents of Canada, and to facilitate reasonable access to health services without financial or other barriers"(p. 5). The Canadian Multicultural Act of 1988 also makes a commitment to "ensure that all individuals receive equal treatment and equal protection under the law" (p. 3). In addition to such legislations, there are specific legal and ethical guidelines to ensure that all patients have the right to make their own informed medical decisions, including the right to be notified of all treatment options available (Bowen, 2001). One in five Canadians will experience some form of mental illness in their lifetime (Mental Health Commission of Canada, 2012). Receiving immediate and regular mental health support service is imperative in preventing or treating mental illnesses. However, research has shown that a significant number of people who require such services either delay or avoid seeking them out, intensifying the issues they are experiencing (Madianos et. al, 2011). Increasing utilization of mental health services and early 
intervention has been shown to improve mental health statuses of patients suffering from different mental illnesses, to improve doctor-patient relationships, increase medication compliance, and reduce healthcare costs related to advanced mental illness treatment (Mental Health Commission of Canada, 2013). It is thus important to encourage utilization of mental health services. This qualitative research paper is an in-depth review of the factors that influence immigrants' access to mental health services and aims to examine the systemic barriers that may be causing disparities in access to such services. The paper uses Peterborough, Ontario, as an illustrative example of a small Canadian community facing many of the barriers that will be discussed. It is important to understand how municipal government and service providers can work more efficiently in creating and managing population level changes.

\section{RESEARCH METHODS}

\section{DEFINITION OF NEWCOMERS}

According to the 2011 census, almost $21 \%$ of Canada's population is made up of immigrants (NHS, 2011). Immigrants may also be referred to as racialized population, visible minorities, ethnic minorities, etc. Having so many different descriptors, even within the data collection agencies in the country, makes it difficult to conduct studies looking specifically at this section of the population.

In the context of this paper, the definition of newcomers is very broad and refers to immigrants, refugees, ethnocultural, and racialized groups (IRER). It includes people who were not born in Canada but entered Canada using some form of visa processing (permanent residents, international students, refugees, temporary foreign workers, etc.). It also includes the children of newcomers who may have been born in Canada and are considered second generation 
Canadians. It further includes people who self-identify as belonging to ethnic communities that are traditionally considered non-Canadian, based on their race, culture, or religion. The reason for such a large umbrella term is because it is important to understand that even if someone has spent their entire life in Canada, they may have had different experiences than the general population based on their ethnicity or their home environment, thus making them vulnerable to the risk factors described in this paper.

Another reason for this broad term is because of limitations in the accurate details available on a person's ethnicity, race, or immigration status. Healthcare providers do not always collect such details, and the information is not always included on public reports, making it difficult to find exact numbers. However, this may not be a negative thing. Sharing one's immigration status or ethnicity might lead to discrimination by the service providers and affect outcomes negatively. Organizations such as "No one is Illegal" strive to eliminate discrimination based on immigration status. Through their "Access Without Fear" campaign, the organization strives towards allowing everyone in a city to access essential services safely without fear of being detained or deported (No one is Illegal - Toronto, 2016). This program is discussed later in the paper.

\section{PARAMETERS OF RESEARCH}

Multiple sources were referenced and analyzed when researching the questions posed in this MRP. Initially, an extensive internet search was used to identify significant trends and articles in the areas of immigrant mental health and the utilization of mental health services. This search resulted in some of the major reports published by the Mental Health Commission of Canada (MHCC) (2012, 2013), Public Health Agency of Canada (PHAC) (2015), World Health Organization (WHO) (2014), and Statistics Canada's documents on ethno-cultural diversity and 
immigration demographics (NHS, 2011). These reports are a rich collection of past and current literature in the area of immigrant mental health and usually include a section on recommendations for changes in practices and policies. These reports made for a robust literature review and a sound jumping board for further research. Following this, the Ryerson Library database, Digital Commons database, and PsycINFO peer-reviewed journal article database were utilized to search for recent articles on some of the specific issues identified, such as women's health, refugee issues, and barriers faced by immigrants. Once these were examined and all new research ideas exhausted, the bibliographies of some of the groundbreaking papers were used to ensure that relevant information was not missed. This form of investigation was used to collect all available material on the topic and to identify gaps in research that may exist.

\section{KEYWORDS USED}

The keywords used for the initial search to identify major topics of interest included the following: immigrant, ethnic minority, mental health, access, barrier, utilization, cultural competence, cultural sensitivity, Canada, Ontario, Peterborough, healthcare policy, social determinants, stigma, and language barrier. These were used in different combinations to generate the most relevant sources.

\section{TIMEFRAME}

Since this is a newer area of research, with specific Canadian information not dating back further than 20 years, no articles were eliminated due to timeline. However, greater attention was paid to newer articles by authors known to work in this field of research. 


\section{GEOGRAPHY}

Even though the focus of the paper is Canada, with examples drawn from Peterborough, research was not restricted to Canadian literature. Research from the United States was also identified as relevant in some cases to draw parallels and find applicable recommendations.

\section{Peterborough}

Research on immigrants is usually focused in bigger city centres, like Toronto or Vancouver, where there are a large number of immigrants and much more diverse service delivery networks and providers. Rarely are studies carried out in areas with lower immigrant populations. This lack of research means that the needs of immigrants in smaller communities may get ignored or remain unmet and fewer initiatives are focused towards providing the same services to them. Peterborough is one such community. Peterborough is located about $150 \mathrm{kms}$ north-east of Toronto and $270 \mathrm{kms}$ south-west of Ottawa with a city population of 74,600 and a county population of 135,000 (City of Peterborough, 2016). Ethnic minorities make up about 3\% of the population, compared to $56 \%$ of the Toronto population. Peterborough's ethnic population is expected to increase steadily over time, especially with an influx of Syrian refugee families. The city is expected to receive 180 Syrians by the end of 2016, with more arriving in 2017 (Kovach, 2016). Other counties around Peterborough experience similar demographic conditions and similar barriers to accessing services.

\section{LIMITATIONS OF CURRENT RESEARCH}

Experiences and behaviours of people are different based on their cultures, beliefs, and situations. However, there is a tendency in the literature to clump diverse IRER (immigrants, refugees, ethnocultural, and racialized) groups together as a single population (Hansson, Tuck, Lurie, \& McKenzie, 2010). This clustering can get in the way of understanding the needs of the 
specific populations and hinder the development of equitable, specialized support systems. However, due to the lower number of immigrants in Peterborough and the absence of any research specific to this concept, it is important to find a starting point to understand the difference in experiences between immigrants and the general population and identify barriers preventing optimal utilization of resources. Once these barriers are identified, they can be targeted from a more systemic level.

Many of the barriers discussed here are not necessarily limited to the immigrant population, but the solutions developed to tackle the problems may be different for that population. Thus, it is important for policy makers to consider the needs of immigrants when developing solutions since a one-size-fits-all approach is likely to be ineffective and waste precious resources. Also, it is important to note that not all the barriers discussed in the paper were found to be in play within Peterborough, but it is important to be aware of the potential barriers that may come into play.

\section{IMPORTANCE OF MENTAL WELL-BEING/ COST OF MENTAL ILLNESS}

The Centre for Addiction and Mental Health (CAMH) and the Mental Health Commission of Canada (MHCC) released a report in 2012 looking at the issues faced by IRER (immigrants, refugees, ethnocultural, and racialized) groups. This report compiled a very thorough literature review of the mental health needs and availabilities of the IRER populations, examined national strategy papers for improvement in mental health, and provided options for service development and initiatives across the country that may improve service provision. The paper highlighted major areas of current research in the field and also recommended areas needing further research. 
Mental health is defined as "a state of well-being in which every individual realizes his or her own potential, can cope with the normal stresses of life, can work productively and fruitfully, and is able to make a contribution to her or his community" (WHO, 2014). Mental illness, on the other hand, is characterized by "alterations in thinking, mood or behaviour associated with significant distress and impaired functioning” (Public Health Agency of Canada - PHAC, 2015). Mental illnesses or psychological disorders include anxiety, depression, schizophrenia, and alcohol and substance dependency (WHO \& CGF, 2014). The lifetime prevalence of mental illness in Canada is estimated to be about 1 in 3 individuals (Pearson, Janz, \& Ali, 2013; PHAC, 2015). In any given year, one in five people in Canada experience a mental health or addiction problem (MHCC, 2012). In 2012, approximately 2.8 million people over the age of 15 reported symptoms consistent with a mental or substance abuse disorder in the previous 12 months, including a major depressive episode, bipolar disorder, generalized anxiety disorder, and abuse of or dependence on alcohol, cannabis, or other drugs (Pearson et al., 2013).

However, mental health should not be defined as simply an absence of mental illness; these are not mutually exclusive conditions. Many people experience sub-threshold mental disorders; their mental illnesses do not reach diagnosis levels, but their mental health is not considered optimal (WHO \& CGF, 2014). Globally and in Canada, there needs to be a shift of emphasis towards preventing common mental illnesses and promoting overall mental wellness, as many triggers of mental illnesses are ingrained in the social, economic, and political aspects of daily life.

In Canada, support services and treatment options for mental illness are made available through different providers in the healthcare system, including family physicians, psychiatrists, hospitals, outpatient clinics, and community agencies (PHAC, 2015). Many people also pay out- 
of-pocket for treatment from private practitioners, such as psychotherapy or residential care services (PHAC, 2015). The detrimental effects of mental illness on the physical, mental, and emotional well-being of an individual have long been researched. According to the Global Burden of Disease Study, self-harm was the fourth largest cause of years of life lost to premature death (GBD, 2010). Exposure to excessive levels of stress over a prolonged period of time (chronic distress) may lead to serious health conditions, such as hypertension, heart disease, weakened immune system, sleep disorders, and obesity, as well as depression, alcohol abuse, and suicide, resulting in significant costs to individuals and society (APA, 2015; Goh, Pfeffer, \& Zenio, 2015, Wild, Wolfe, Wang, \& Ohinmaa, 2014). Research on stress has shown that about $75 \%$ of all visits to healthcare providers result from stress-related disorders, and the annual cost of work-related stress in Canada is estimated to be between 2.9-11 billion dollars, and about 300 billion dollars in the United States (Hassard et al., 2014; US Department of Health and Human Services, 2001). Indirect costs related to mental illness have been shown to range from 11-50 billion dollars in Canada (PHAC, 2015). In 2014, only 67.1\% of Peterborough's population over the age of 12 reported to have very good or excellent mental health, compared to $70.4 \%$ of Ontario (Vital Signs, 2016).

One group who are regularly exposed to different and greater levels of stress than the general population is IRER groups. As noted above, IRER groups include immigrants, refugees, or other ethno-cultural and racialized groups. Uprooting one's life and resettling somewhere entirely new without knowledge of services, rights, or future possibilities can be highly stressful and is considered to be an experience that causes a significant amount of distress. Mental wellbeing can help mitigate the negative impacts of such stressors, a necessary focus for Canada, due to its large immigrant population. 


\section{SOCIAL DETERMINANTS OF MENTAL HEALTH}

Since the cost of mental illness is so high, both economically and in terms of lives lost (APA, 2015; GBD, 2010; PHAC, 2015), it is important to try to understand the most effective methods of preventing mental illness and promoting mental well-being. Implementing such solutions is not always as easy as it sounds. As described by WHO (2002), there is a dilemma in defining what exactly one wants to prevent. When it comes to a biological disease, prevention programs can occur in three stages, primary, secondary, or tertiary. Primary programs prevent the disease itself (through lifestyle changes or avoiding transmission), secondary programs reduce the severity of the disease (through early screening or detection), and tertiary programs reduce the associated disability (by providing access to high quality treatment options) (Gordon, 1987). Often, mental disorders do not have clear cut etiologies where such focuses can be implemented. An individual may suffer below-diagnosis levels of depression for many years and never reach diagnostic levels, but will continue to experience the negative impacts of the disease. Therefore, it is important to reach individuals at different stages of disease development to potentially prevent, or, at least reduce, impact of the disease.

Prevention strategies and educational programs can begin on a universal scale that reaches the entire population. They can then be targeted towards groups that are at significantly higher risk of developing mental health disorders. Finally, these strategies can be narrowed to focus on specific individuals at highest risk (Gordon, 1987). This final stage is where the promotion of mental well-being is of utmost importance. Promotion of mental health can be defined as "the operation by which we improve the place which mental health occupies on the scale of values of individuals, families or societies" (WHO, 2002, p. 8). Thus, if people value mental health more, they will be more motivated to improve it. Another definition of mental 
health promotion is "the enhancement of the capacity of individuals, families, groups or communities to strengthen or support positive emotional, cognitive and related experiences" (WHO, 2002, p. 9). Prevention aims to avoid disease while promotion looks to improve health and well-being. Any program that seeks to reduce mental illness needs to have a two-pronged approach addressing both these aspects. The social determinants of mental health include factors that can influence both these issues and, for that reason, they need to be examined carefully before program implementation.

Mental health, like physical health, is strongly associated with social factors that are often referred to as social determinants of health. These factors are thought to interact with one another and contribute to improving or worsening the health of individuals (Mikkonen \& Raphael, 2010). An important focus of these factors involves disparities or inequalities in the availability of the determinants. A person privileged with higher availability of factors that positively influence mental health is likely to have a higher mental well-being, when compared to someone who does not have that privilege. Thus, to enhance mental well-being and reduce inequalities in mental health, solutions and interventions need to stem from sectors that exert influence on the social determinants so that they strengthen the ability of individuals to cope with experiences that negatively impact their mental well-being.

The Public Health Agency of Canada (PHAC) lists the following key determinants of health: 1) Income and social status, 2) social support networks, 3) education and literacy, 4) employment/working conditions, 5) social environments, 6) physical environments, 7) personal health practices and coping skills, 8) healthy child development, 9) biology and genetic endowment, 10) health services, 11) gender, and 12) culture. In addition to these factors, IRER populations are exposed to further factors that have been linked to mental health problems, such 
as perceived racial discrimination, language difficulties, and migration (Hansson et al., 2010). Some of these factors have been examined below in more detail.

\section{EDUCATION, EMPLOYMENT, INCOME, AND STATUS}

Education and employment are both very crucial factors influencing mental health.

Education is highly correlated with employment and financial success (Mikkonen \& Raphael, 2010). Higher education can lead to advanced training and enhanced professional development, resulting in better job opportunities. Lack of employment can lead to material and social deprivation, physical and psychological stress, and an increase in unhealthy coping behaviours (Mikkonen \& Raphael, 2010). Financial deprivation can make it difficult to participate in cultural, educational, and recreational activities, leading to social isolation (Mikkonen \& Raphael, 2010). A study by Nordt et al. (2015) found that unemployment increased the relative risk of suicide by $20-30 \%$ in all four regions of the world that were examined, regardless of age or sex.

The work environment is another important aspect to consider. High-stress jobs can predispose individuals to psychological and physical ailments, such as depression, high blood pressure, or work-related injury (Mikkonen \& Raphael, 2010). Lack of appreciation from employers, higher demand on time without fair compensation, and lack of control over working conditions can lead to a high-stress work environment.

Higher income and social status have been linked to better health due to increased access to essential services, like food and housing, as well as services that enhance the quality of life (Mikkonen \& Raphael, 2010). Research has shown that wealthier populations have a longer life expectancy (Wilkins, 2007). Historically, immigrants have experienced lower income levels than 
the general population, even when their length of stay in Canada is controlled (Picot \& Hou, 2014), and have been more likely to accept precarious work. However, the same study found that income discrepancy has been reducing since the 2000s, in large part due to changes in the immigration policies governing the selection of the Federal Skilled Workers Program, as well as the introduction of the Provincial Nominee Program. These programs have increased the number of higher skilled foreign workers entering Canada, resulting in higher job prospects.

\section{SOCIAL SUPPORT AND SOCIAL EXCLUSION}

Social support is considered to be "a range of interpersonal exchanges that provide an individual with information, emotional reassurance, physical or material assistance, and a sense of the self as an object of concern" (Pilisuk \& Parks, 1980, p. 158). The results of a study conducted in Metropolitan Toronto concluded that social support correlated with general health status (Wright, 2006). Furthermore, researchers have shown reduced mortality rates amongst cancer patients and HIV-infected individuals who had higher levels of social support (NolenHoeksema \& Rector, 2008). It has been proposed that social support acts as a stress buffer, providing a mediating effect on depression. Social support can also enhance the sense of belonging to a community, expedite integration into society, and alleviate feelings of loneliness and isolation (Nolen-Hoeksema \& Rector, 2008).

Availability of social support is also believed to have an impact on the mental health of immigrants. Relocating to a new country imposes many social challenges on this group, such as developing a new social network, adjusting to a new lifestyle, and learning a new language. Although social support may be culturally defined, it still significantly impacts the ease of resettlement, and lack of social support can hinder this process (Stewart et al., 2008). New immigrants may suffer from social exclusion through lack of social networks, lack of extended 
family support, and through conflict of gender and generational roles in their new country. These factors represent a lack of 'social capital' that would otherwise be available to them in their country of origin.

Social exclusion leads to the marginalization of already vulnerable populations, resulting in lower rates of employment, limited access to health and social services, and reduced access to training and development opportunities (Mikkonen \& Raphael, 2010). Many immigrants are restricted from practicing in their professions, such as medicine or engineering, due to regulations requiring Canadian-specific training. Yet, little help exists to assist them in accessing the required training. This lack of opportunity for immigrants to pursue their intended career may force them to take on jobs far below their qualifications, further creating a sense of hopelessness and powerlessness. Many immigrants are financially responsible for family in their home countries and require regular funds to send back, leading to a more urgent demand to gain employment. This leads to a cyclic effect where they are unable to access higher training, betterpaying jobs, and higher quality of health services, which serves to marginalize them further.

The sense of belonging to a local community also plays a vital role in mental well-being. Sense of belonging is the "experience of being both personally involved and integrated within an environment or system" and refers to feeling valued, needed, and important within an environment (McCallum \& McLaren, 2011, p. 84). It also encompasses one's sense of being a valued and important part of a group (Hagerty, Williams, Coyne, \& Early, 1996). McCallum and McLaren (2011) demonstrated that a lack of sense of belonging to a community was significantly associated with depression in gay, lesbian, and bisexual adolescents, and found that a deeper sense of belonging decreased feelings of isolation while increasing psychological well-being. 
Research on immigrants has also demonstrated that a higher sense of belonging to the community mitigated chronicity of distress in this population (Chowdhury \& Fowler, 2011).

\section{Health Services}

A high quality of care is a human right and a part of the universal healthcare system in Canada. According to the Health Canada Act of 2005, everyone must have "reasonable and uniform access to insured health services, free of financial or other barriers" (p. 7) and "no one may be discriminated against on the basis of such factors as income, age and health status" (p. 7). Yet, the Ontario Health Insurance Plan (OHIP) is not available to newcomers for the first three months of their stay, and when it does become available, it does not cover the cost of medication, vision, and dental care (OHIP, 2015). OHIP is discussed further in the section on barriers.

\section{Culture and Health Practices}

Culture is a pattern of ideas, customs, and behaviours shared by a particular group of people or society, and it is ever evolving (Mayhew, 2016). Culture plays an important part in all aspects of our lives. Cultural practices can range from the kinds of food eaten, to self-care practices, and the understanding of illnesses. In a broad definition, cultures can be divided into one of two groups based on whether they are individualistic, where the focus is the individual, or collectivist, where everyone works towards the betterment of the group as a whole. In each type of culture, the road towards resolving a problem can be very different. Perception of disease may vary between cultures, as may the cause of the disease. There may be differences in whether a certain culture accepts certain diagnoses, or even seeks help for some problems. When seeking assistance, differences in communication styles may lead to challenges in the understanding of the symptoms between patient and physician. In some Eastern cultures, communing with nature or God is common, but describing such actions to a caregiver unfamiliar with this concept may 
lead to a diagnosis of psychosis or schizophrenia, resulting in an incorrect treatment plan. Moving to a new place comes with many different challenges, one of them being how to negotiate our own cultural practices and incorporate them into the lifestyle of the host country.

\section{AGE AND GENDER}

Gender differences in mental health have been extensively studied. According to the literature, gender is one of the most prominent determinants of depression (Cook, 1990; Wareham, Fowler, \& Pike, 2007), and women are diagnosed with depression twice as often as men (Albert, 2015; American Psychiatric Association, 1994). Social support has been proclaimed to be a major contributor to such gender differences. One researcher suggested that since women tend to have more intimate relationships, they are more susceptible to distress in the lives of their network (Riley \& Eckenrode, 1986). Another hypothesis claimed that men who rely on a female support network are more advantaged than women who rely on male support because women are typically more nurturing, perhaps due to their nurturing social role (Wareham et al., 2007). Beiser and Hou (2001), as well as Takeuchi et al. (2007), demonstrated that women born outside of the US were less likely to experience any psychological disorders when compared to women born in the US. The source of this discrepancy is unclear, and it is important to examine the degree to which social support plays a role.

Lack of pay equity, or the gender wage gap, is another major source of distress for women. This wage gap disproportionately affects low-income women, visible minority women, and indigenous women. In 2011, female workers in Canada earned 66.7 cents for every dollar earned by men (Statistics Canada, 2013). In Canada, gender inequality may also arise from lack of affordable, high-quality child care services. This forces women to leave the workforce and remain at home to look after their children while their male counterparts stay in the workforce 
(Mikkonen \& Raphael, 2010). Lack of child care services puts an even higher burden on single mothers, who are also more likely to suffer the consequences of food insecurity due to poverty (Mikkonen \& Raphael, 2010).

Immigrant women may also face barriers while joining the Canadian workforce due to cultural practices and restrictions. They may also experience further distress due to incongruity in gender roles between their home country and Canada (Spitzer, 2011). In many cultures, women are the caregivers while men are the earners. Such roles may be reversed when they move to Canada. Only $24 \%$ of immigrant women work once they move to Canada, most of which are restricted to the sales and service sector with low pay, high stress, and no control (Spitzer, 2011). These women may be supporting the family financially while their spouses wait to update their professional credentials (Chui \& Maheux, 2011). Such role reversal can lead to the men feeling emasculated and experience a lack of power and control.

There is a three year undertaking for those who sponsor their spouses to join them in Canada (CIC, 2016). An undertaking is a promise of support that holds the sponsor financially responsible for the basic needs of the spouse, even if the sponsor's financial situation changes or the relationship breaks down (CIC, 2016). During this three year period, sponsored women may feel obligated or forced to stay with their spouses no matter the living situation due to lack of knowledge of their rights and fear of being deported if they leave their spouse.

Children in immigrant families sometimes take on nontraditional roles when they move to Canada. Children learn the new language faster than adults and may be required to play an interpreter function. This can create a shift in the power balance of a family structure and cause friction between family members. Adolescents also face additional challenges when confronted 
with peer pressure to conform to the popular norms, especially when these behaviours go against cultural values (Amri \& Bemak, 2013). Examples include dating and working while in school. Such social pressures to conform to the mainstream values can put an immigrant child in a vulnerable situation. They may experience anxiety and depression, which in turn creates the need for them to access culturally-sensitive mental health services to help reconcile these pressures (Amri \& Bemak, 2013).

\section{RACISM AND DISCRIMINATION}

A major source of mental trauma for some immigrant populations is experiencing racism and discrimination. According to Harrell (2000), racism is "a system of dominance, power, and privilege based on racial group designations; rooted in the historical oppression of a group defined or perceived by dominant-group members as inferior, deviant, or undesirable; and occurring in circumstances where members of the dominant group create or accept their societal privilege by maintaining structures, ideology, values, and behaviour that have the intent or effect of leaving non-dominant group members relatively excluded from power, esteem, status, and/or equal access to societal resources" (p. 43). Discrimination is an action or a decision that treats a person or a group negatively on the grounds of their race, religion, sex, sexual orientation, etc. (Canadian Human Rights Commission, 2013). Examples include someone experiencing racism first-hand when harassed by police because of their looks, which displays their race, culture or ethnicity, and experiencing racism second-hand through others, such as hearing about the experiences of 9/11 attack suspects. Such experiences can be traumatic and induce high levels of stress among immigrants. In November 2015, Muslims in Peterborough were victims of direct discrimination that culminated in an attack on the only mosque in the city, leading to city-wide panic and fear. One way to deal with such actions is for the community to stand united against 
the perpetrators of such hateful actions and let the victims know that the actions of the few do not reflect the views of all. Peterborough is a shining example of this behaviour. The incident not only brought the community together and caused people to stand up for one another against hate, it encouraged collaborations between churches, the synagogue and the mosque, something that is quite uncommon in many communities.

Social identity threat is a dangerous effect of perceived discrimination in adolescents. Social identity theory assumes that individuals try to maintain a positive perception of the groups they belong to and when their positive perceptions are challenged, for example, when experiencing discrimination, individuals experience a sense of threat, which can manifest as negative emotions (Tajfel \& Turner, 1986). Social identity and self-worth in adolescents are usually derived from their membership and identification with various social groups, like in school or with cultural groups. Baysu et al. (2016) found that perceived discrimination in school-aged children significantly predicted lower academic success, while the perception of equal treatment acted as a buffer against disengagement and poor performance.

\section{LANGUAGE DIFFICULTIES}

Language is an important tool in maneuvering through society. English language proficiency may allow immigrants to move outside of their immediate social circles and promote the development of new social connections, find better job opportunities, increase coping mechanisms, and promote quicker acculturation (Beiser \& Hou, 2001; Takeuchi et al., 2007). Research demonstrates that limited English skills represent a significant barrier to securing a well-paying job and advancing in the workforce (Batalova \& Fix, 2010). Beiser and Hou (2001) found that $8 \%$ of the refugees spoke no English even after ten years of living in Canada. Since language proficiency is also related to employment opportunities, it is possible that the two 
factors are linked. Language related difficulties will be discussed later in the paper when examining the barriers to utilization of mental health services.

\section{MIGRATION}

The act of migration itself is a process that can induce stress and hamper the mental wellbeing of individuals. The conditions under which someone moved, the social connections they left behind, and the need to adapt to their new life all impact mental health.

Age at immigration may have an impact on the mental health of immigrants. Those who immigrated at a young age have a better chance of becoming proficient in the language and expanding their social groups through school and other extra-curricular activities with their peers than immigrants who entered Canada later in their life (Takeuchi et al., 2007). Chinese immigrants who migrated after the age of 20 have been shown to have 1.5 to 3 times higher prevalence of major depression than those who migrated before the age of 20 (Takeuchi et al., 1998). Research has shown time and again that increased length of time in Canada is also associated with lower chronicity of distress. Beiser and Hou (2001) suggest that over time, immigrants may form more ethnic community connections, develop higher language proficiency, and increase their chances of employment. It is also likely that due to increased social support, immigrants, who normally have lower rates of mental health service utilization, are aware of services available to them and are more likely to use them.

\section{MENTAL HEALTH SERVICE UTILIZATION}

One sector of the population that may be under higher levels of stress than the general population is immigrants. With almost 7 million members of the population being foreign-born (NHS, 2011), Canada prides itself as a multicultural and inclusive society. But looking under its 
figurative skirt reveals a healthcare system plagued with disparities between the health of immigrants and the general population, inequalities in quality of care, delays or absences of appropriate services, and underutilization of resources (Beiser, 2005; Hansson et al., 2010). Only over the past decade or two has this issue come under scrutiny, resulting in the Mental Health Commission of Canada (MCSS) establishing a Diversity Task Group to inform and make recommendations to the Commission on health and social problems affecting IRER groups. Research in this population has focused on the social determinants of mental health, the rate of mental illness, and barriers to care. Many barriers have been identified as responsible for the lower access and utilization of health services by the IRER (immigrants, refugees, ethnocultural, and racialized) population, including lack of health insurance or knowledge of available services, language barriers, and low cultural competency of healthcare providers (Donnelly, Hwang, Este, Ewashen, Adair, \& Clinton, 2011; Hansson et al., 2010; Pottie, Ortiz, \& Kuile, 2007).

A large number of research studies conducted in multiple countries on different ethnospecific communities reveal that their rates of mental health service utilization are well below the country's norm. A report by the Substance Abuse and Mental Health Services Administration (SAMHSA, 2015) suggests that only $4.9 \%$ of Asian American adults and 7.3\% of Hispanic Americans utilized mental health services over the last year, compared to $16.6 \%$ of Caucasian Americans. Canada, a country where healthcare services are publicly funded, also experiences similar inequalities in utilization of mental health resources. The Canadian Chronic Disease Surveillance System (CCDSS) (supported by the PHAC, is a collaborative network that tracks the prevalence and incidence of chronic illness) reports that $14.4 \%$ of Canadians aged one year and older (about 5 million people) received health services for mental illnesses in the year 2009/2010 (PHAC, 2015). Tiwari and Wang (2008) conducted a nationwide study to compare 
mental health service use by ethnicities and found that all non-white ethnicities in the study had lower rates of utilization than those identifying as white. Further, an Ontario-based study found that illness severity was higher at hospital presentation for Chinese patients, indicating that there is a larger delay between the onset of symptoms and help-seeking in this population (Chiu et al., 2016). Other studies have also shown lower utilization of mental health services by ethnic minorities (Barron et al., 2010; David, 2010; Tiwari \& Wang, 2008). Another Canadian study examined whether the availability of a universal healthcare system influenced ethnic minority populations to increase mental health utilization (Kirmayer et al., 2007). They found that, even after controlling for other variables, the ethnic minority population demonstrated a lower utilization of mental health services. To increase mental health services utilization, it is first important to understand what factors play a role in deciding whether or not to seek help.

The Behavioural Model of Health Service Use, developed by Andersen in 1968, has been widely used to understand the motivations for utilizing healthcare services. Andersen himself has regularly adapted this theory over time to reflect the ever-changing needs of people and economics. The most commonly used version was developed in 1995, with the final model presented in Figure 1. 

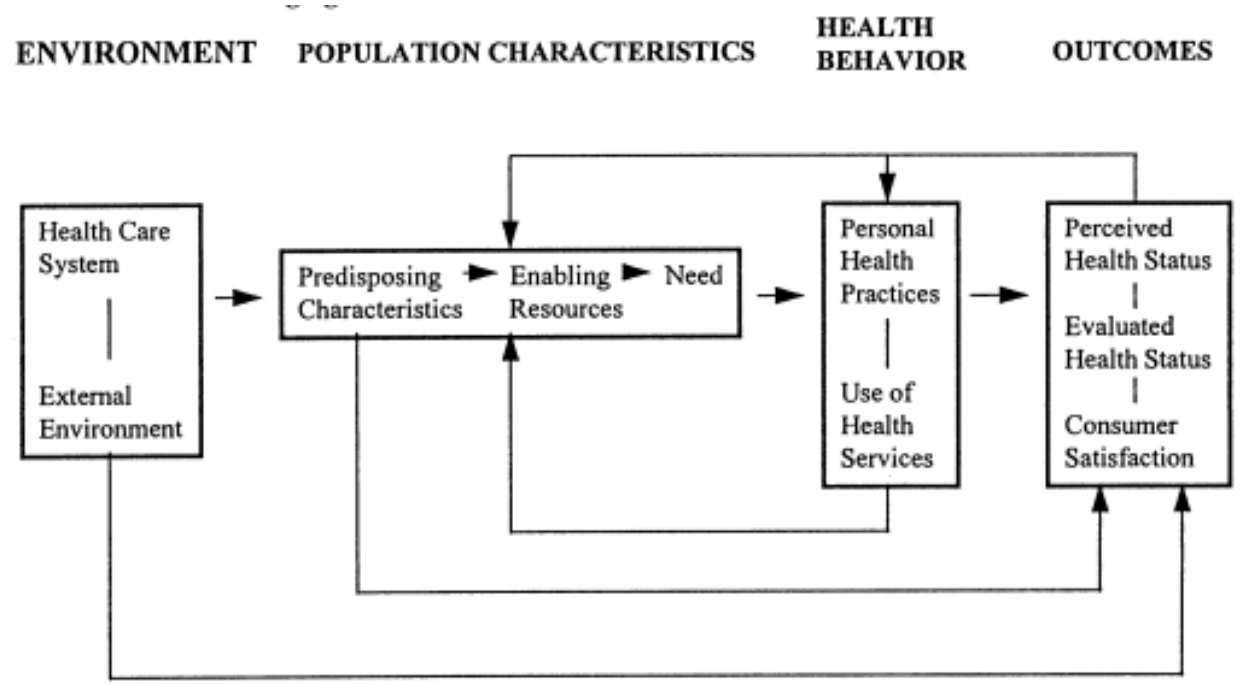

Figure 1: Behavioural Model and Access to Health Care.

According to Andersen, a person's use of services may be a function of their "predisposition to use services, factors that enable or impede use, and their need for care" (Andersen, 1995, p. 1). Predisposing factors include demographics, social characteristics, and individual beliefs (like age, gender, marital status, length of time in the country, and education level). Enabling factors include personal resources that facilitate or impede access and availability of services in the community. These include language proficiency, income, and insurance coverage. Need factors are an individual's self-perceived need for treatment and a practitioner's evaluation of a disease. For example, in order for someone to decide to access a healthcare service, they need to experience the need for the service, have the knowledge of what service to access, and the means of transporting themselves to the service location. On top of that, they need to feel that the need for service is great enough to skip work if their previous experiences with the healthcare system has been positive or not, and if they have the financial means to pay for the service. All of these factors combine together to lead to a behaviour of helpseeking or not help-seeking. These factors are closely linked to the social determinants of health 
and illustrate how the different determinants of health interact with each other to influence behaviour.

\section{DISCUSSION OF BARRIERS TO SERVICE UTILIZATION}

According to the 2001 U.S. Surgeon General's report, "Mental Health: Culture, Race, and Ethnicity," many of the differences in mental health service utilization were a result of structural barriers, such as lack of transportation, low availability of care providers, cost, and insurance barriers. According to SAMHSA (2015), the severity of mental illness, the cost of services, and insurance coverage (or lack of) were the most commonly cited reasons not to utilize mental health services. Park et al. (2013) cite multiple sources discussing cultural beliefs, stigma, shame, the level of acculturation, and perceived lack of benefits as some other reasons for lower rates of utilization among ethnic minorities. There is also evidence that certain cultures tend to somaticize their illnesses as an expression of their symptoms, thus avoiding diagnosis (Park et al., 2013; Leong \& Lau, 2001).

The majority of new immigrants are unfamiliar with the preventative and treatment practices of Canada, and often their first point of contact with the healthcare system is through the emergency department or word of mouth (PASS, 2008). Talbot et al. (2001) analysed the Canadian National Population Health Survey data and found that being a recent immigrant was significantly associated with not having a family doctor. Recent immigrants may also be unfamiliar with where to go, how to make an appointment, or what type of screening programs, such as mammograms or cervical cancer screening, are available to them. Studies conducted in the US have shown that Latinos with limited English proficiency reported 22\% fewer physician 
visits than native speakers and that the effect of limited language proficiency was "similar to effects of having poor health, no health insurance, or no regular source of care" (PASS, 2008).

There is a significantly lower rate of utilization of programs among immigrants compared to the general population (Bowen, 2001). Some reasons provided for this disparity look at the difference in insurance coverage, cultural beliefs, discrimination, and different socio-economic status. Other possible explanations may be more related to lack of knowledge of the healthcare system or the access to interpreter services. Multiple studies in the US and the UK, as discussed by Bowen (2001), found that utilization of screening programs was more related to language barriers than health or cultural beliefs. Examining barriers to utilization of services is a daunting task, mostly due to the extensive list of barriers that exist, and the even larger list of potential solutions that can be used to address them. In an effort to make this challenge easier to understand, researchers have divided the barriers into three levels: system level barriers, provider level barriers, and patient level barriers (Hansson et al., 2010; Pottie et al., 2007).

Barriers at the system level include issues like delay in qualifying for medical insurance for newcomers, shortage of family physicians accepting new patients, lack of cultural and language interpreters, lack of continuity of care between multiple agencies, etc.

Barriers at the provider level include lack of effective screening protocols and prevention guides for physical and mental health concerns, formal vs. informal healthcare providers, lack of cultural competency training, and lack of time that practitioners have to spend with their clients, as well as clinician payment structure based on the number of patients seen.

Barriers at the patient level may include long wait lists or lineups, fear of being stigmatized, lack of knowledge of services, discrimination, language barriers, lack of 
appreciation of benefit of prevention, being in a form of survival mode due to competing life demands, lack of financial ability to pay for care, lack of access to continuous care, lack of insurance, and gender barriers.

Access to mental health and counseling services is of particular concern for individuals with limited language proficiencies. Immigrants and refugees face severe challenges in seeking out specific mental health services that are unique to their circumstances. These can range from cultural and religious stigma, lack of trust in government organizations, family pressures, and mental health manifesting as physiological symptoms (Bowen, 2001). These barriers are exacerbated by a lack of interpreter services provided by mental health agencies. Many studies have demonstrated that even when immigrants access healthcare services they delay utilizing mental health services, domestic violence services, addiction services, and sexual assault services due to language barriers (Bauer, 2000; Bowen, 2001). In many instances, instead of providing language services, immigrants are sent to settlement agencies for general support, resulting in a two-tier level of care (Canadian Task Force on Mental Health Issues Affecting Immigrants and Refugees, 1988).

Barriers, such as those mentioned above, trickle through all aspects of a newcomer's life and they have to learn to negotiate such obstacles as they adapt to life in Canada. However, there is an onus on the healthcare system to facilitate proper access to care. As Luther points out in her essay on changes to the social service delivery since the '70s (2007), there was a significant push to develop culturally sensitive social programs as a result of Project 4000. The goal of Project 4000 was to privately sponsor 4000 new refugees who had entered into Canada after the Vietnam War. The influx of people who were culturally, racially, and linguistically different from the mainstream "exposed the institutional limitations and Eurocentric biases of existing social 
programs and services" and their inability to handle the needs of the newcomers (p. 40). Local service sector agencies took on the role of providing specialized services to these newcomers, and advocated for their rights. The government, in turn, rid itself of settlement-related services and service delivery, increasing the workload on these organizations. This shift increased the systemic gap between "us" (mainstream services) and "them" (immigrant-specific services) and placed the onus on the immigrant to "adapt, adjust, and accept existing limitations" in services available to them. The following section examines some specific barriers that newcomers face regularly. The section comprises of a detailed study of the barriers faced by most newcomers to Canada, and not just specific to newcomers in Peterborough. Peterborough-specific examples have been provided where relevant.

\section{ACCESS TO HEALTHCARE PROVIDERS}

Barriers to accessing care start early on for newcomers. In Ontario, there is a three-month waiting period before qualifying for OHIP (OHIP, 2015). It is recommended that individuals buy private insurance packages to cover them during that time, but these packages can be very expensive and unaffordable. This lack of coverage results in newcomers being unable to access services in the early days when they are first getting themselves acquainted with the services. Once the three months are over, the next challenge is usually to find a physician who can provide regular access to care. According to Statistics Canada, 4.5 million (14.9\%) Canadians in 2014 did not have a regular medical doctor (2015). Family physicians usually handle most non-urgent cases and patients require referrals to be able to see specialists for specialized care. Those without a family physician often access care through walk-in clinics or emergency departments (CMA, 2009; On the Coast, 2016), a practice less than ideal, due to increased wait times for patients and a higher cost to the system. No data was found on the length of time it takes for 
individuals to find a family physician in Peterborough, but anecdotal evidence suggests that the wait is quite long.

A search on the College of Physicians and Surgeons of Ontario website reveals that there are 135 family physicians practicing in at least 11 unique locations in the city of Peterborough. The city has only one walk-in clinic, with the second one closing its doors permanently in January 2016. Upon examining the availability of mental healthcare providers, it was found that Peterborough has 14 psychiatrists, almost all of whom are working in the city's only hospital (College of Physicians and Surgeons, 2016). This is a systemic issue since most specialists are more or less forced to practice out of hospitals. A search in the College of Psychologists of Ontario website shows that Peterborough has 40 registered psychologists, of which 30 are currently authorized to provide services. Services from private psychologists are not covered by OHIP and are usually paid for by users out-of-pocket or through extended private insurances. Peterborough also has multiple local counselling agencies providing free non-clinical care to clients, such as the Community Counselling and Resource Centre, YWCA Peterborough, Four Counties Crisis, and Kawartha Sexual Assault Centre. Such agencies are very helpful to newcomers as they can provide some support until newcomers are able to access OHIP-covered services. However, these agencies are usually under-funded and are often flooded with huge caseloads (Vineberg, 2014).

In addition to this barrier, OHIP does not cover some of the basic healthcare needs like medication, vision, or dental care. The Healthy Smiles Ontario program offers free preventative, routine, and emergency dental services to children under the age of 17 that come from lowincome households. This program is a step in the right direction, but clearly, more is needed to support adults, as well as families that are just above low-income qualification cut-off. 
(Ontario.ca,_2016). Public policy makers and provincial lawmakers need to focus on inequities that exist in accessing healthcare services and work towards removing the barriers discussed in this paper. The implementation of drug, vision, and dental care into the current OHIP system will go a long way to help low-income families, immigrants and non-immigrants alike. Implementing “Access without Fear" programs will also contribute to diminish the fears of detention and deportation that many temporary residents constantly feel (No one is illegal - Toronto, 2016). Some immigrants are even afraid to call 911 for help in fear of being detained. Cities like Toronto and Hamilton have turned themselves into "sanctuary cities" where a person's residency status will not be an impediment in receiving necessary services (Keung, 2014). Employers that provide group benefits to their employees have the ability to cover the cost of private mental healthcare services through insurance, and such benefits can go a long way towards ensuring quick and accessible care.

\section{ACCESS TO TRANSPORTATION / TIME}

The density of available services is a major factor when looking at access. Like many larger cities, most of the resources in Peterborough are concentrated in the downtown core. These organizations have vast catchment areas due to lack of multiple service providers nearby. This is an issue for people who may live in the outskirts of the city. These areas are not serviced by Peterborough public transit and usually can only be accessed by personal vehicles. Such a situation creates an access barrier for those who need the services but cannot reach them.

Lack of time may cause another similar barrier to accessing care. Most non-hospital care providers work on a regular 9-5 weekday schedule. If an individual works during those times and has no opportunity to take time off work to get help, either due to lack of understanding of their rights or due to undue manipulation from employers, individuals may choose to avoid seeking 
help rather than missing time off from work. Such a barrier may, in fact, negatively impact men more than women, since more newcomer men are likely to work during the day (Robinson, Taft, \& Turley, 2010).

\section{LANGUAGE BARRIERS}

The need to communicate is an inherent part of being human. When open and transparent communication becomes difficult, it gives rise to a sense of unsettlement and a feeling of being unfulfilled in life. Linguistic abilities are critical when accessing services, and are a large contributor to health disparities. Inability to properly communicate with medical professionals can lead to inappropriate or mistaken diagnoses, higher rates of treatment dropouts, recurrent hospitalizations, and increased risk of medical errors (Brisset et al., 2014). According to the 2011 census, one-fifth of the Canadian population speaks a language other than French or English at home.

Inability to communicate with healthcare providers, even when seeking help, can be a major issue. Poor patient-provider communication is closely linked with poorer health outcomes, increased number of misdiagnosis, lower patient satisfaction of care, lower patient understanding of their condition and treatment options, reduced adherence to treatment regimes, less knowledge and use of preventative medicine, and higher cost of healthcare (Bowen, 2001; PASS, 2008). In fact, Canadian researchers agree that language is the most common barrier faced by immigrants when seeking mental health services (Canadian Task Force on Mental Health Issues Affecting Immigrants and Refugees, 1988; PASS, 2008).

There is an increasing awareness that immigrants with low levels of language proficiency may be underserved in the health system due to unequal access to health services, resulting in 
unmet needs and an inferior quality of care (Bowen, 2001; PASS, 2008). Studies have found that patients with low language proficiency who were not accompanied by an interpreter were likely to receive poorer quality of service, fewer medications, fewer tests, poorer control of non-pain symptoms, and spend less time in the emergency department than those accompanied by interpreters, after controlling for all other socio-demographic factors (PASS, 2008). There is, however, limited literature in the Canadian context that examines the effects of language barriers on health outcomes, utilization of services, patient satisfaction, and cost to the healthcare system. There are also a lack of policies and programs which aim to provide language access to immigrants with lower language proficiency (Bowen, 2001).

According to the 2011 census, 5.3\% of people in Peterborough have a mother tongue that is neither English nor French, compared to $25.7 \%$ in Ontario (Statistics Canada, 2016a). The most common non-official languages spoken in the Peterborough metropolitan area are German (0.8\%), Dutch (0.6\%), Polish (0.4\%), Italian (0.3\%), and Spanish (0.2\%) (Statistics Canada, 2016a). According to the 2011 National Household Survey, 3140 (4.1\%) individuals in Peterborough belonged to a visible minority group (NHS, 2016). In comparison, $25.9 \%$ of the province of Ontario was of visible minority. This leads to a unique challenge for those who are in need of translation or interpreter services in this community. Compared to other urban centres in Ontario, language diversity in Peterborough is much narrower and the availability of interpreters is, therefore, limited. Organizations mostly depend on volunteers who speak the language to help out in times of need. The only other option available is for individuals to travel to Toronto or Ottawa to receive services. 


\section{LACK OF CULTURAL COMPETENCY TRAINING FOR SERVICE PROVIDERS}

Normalcy in mental and physical health is culturally relative, as are the manifestations of disease. Cross-cultural studies have shown a lower prevalence of depression among people in less industrialized nations, but the reason for this discrepancy is now thought to be due to differences in symptom manifestation of depression amongst Western and non-Western participants (Nolen-Hoeksema \& Rector, 2008. Chapter 9, p. 316-317). Loss of self-esteem and lack of interest in pleasurable activities are seen as common symptoms of depression in Western medicine because these emotions are considered to be valuable. However, these are not commonly expressed in other cultures and thus not representative of depression in that population. A study of refugees in Somalia (Carroll, 2004) found that they had a concept, similar to sadness, called "murug". "Murug" was said to arise when an individual lost a loved one or had a major negative event in their life, with the symptoms typically manifesting as headaches and social withdrawal (Carroll, 2004). Similarly, in China, those experiencing chronic depression sometimes complain of neurasthenia, which is a collection of symptoms including headaches, joint pain, nausea, lack of energy, and palpitations. It is thus important for mental health providers to be aware of such differences when treating immigrants and refugees. Even when they are not familiar with the specific differences in cultures and practices, keeping an open mind and showing genuine curiosity towards their clients will go a long way in developing a strong client-provider relationship. Unfortunately, there are no accessible cultural competency training programs currently available in Peterborough.

\section{FEAR OF STIGMA}

Many East Asian cultures attach a significant amount of stigma to mental health illnesses like depression, anxiety, and schizophrenia. Seeking help from mental health services is seen as a 
sign of weakness, lack of faith, and brings shame to the family (Amri \& Bemak, 2013). They also find it difficult to express negative feelings of suicidal ideation or deviant sexual desires due to fear of wrath from God and fear of being judged by their care provider. Individuals are often expected to 'toughen up' and deal with their struggles. Many such cultures also prefer seeking

help from within the family to protect the family from negative public opinion. Such strong stigma often force suffering individuals to internalize these problems and not seek help (Amri \& Bemak, 2013). Issues such as domestic violence and substance abuse are also rarely addressed due to the cultural stigma. For many newcomers, it is essential that the family stay together, regardless of the circumstances. Divorce is usually not seen as an option (Amri \& Bemak, 2013). There is added guilt for Muslim individuals with substance abuse problems because use of drugs and alcohol is prohibited in Islam. As in other cultures, the abuse of drugs and alcohol can lead to family conflict and domestic violence. It is, therefore, imperative to have substance abuse treatment centres available to immigrants from different cultures that take an individual's cultural and religious contexts into account when encouraging utilization and providing treatment options (Amri \& Bemak, 2013).

\section{LACK OF KNOWLEDGE OF SERVICES AVAILABLE}

Newcomers are unlikely to be aware of all the preventative and treatment options available to them in Canada or how to navigate their healthcare and other systems to access care. However, it is clear that language creates a barrier in seeking preventative health services, as well as receiving educational information on health promotion and disease prevention. Studies conducted in the US have shown that Latinos with poor language proficiency reported $22 \%$ fewer physician visits than native English speakers. An effective way of combating the language 
barrier in the mental health field is by providing education and support materials in a language other than English and French. Brochures and other informative materials can be written in the languages most widely spoken. For Canada, this would be Punjabi, Chinese (Cantonese and Mandarin), Spanish, Tagalog, Arabic, Italian, Urdu, and German (NHS, 2011). For Peterborough, the most common non-official languages spoken were Korean, Polish, and Spanish (NHS, 2016). Arabic can be added to this list in order to make information accessible to the 35 new Syrian families expected to make Peterborough their home by March of 2017 (NCC, 2016). There are two approaches to doing this; translating from original documents in English/French, or developing resources based on specific community needs (Bowen, 2001). Having such documents will help educate newcomers on the services they can access in their new community.

\section{DISCUSS HOW TO IMPROVE THE SITUATION}

Research on the difference between immigrants and the general population will continue for as long as the disparities and inequalities between these groups exist. Population level change is never easy, quick, cheap, or always achievable. If change is attempted, it should be done using all the right tools in order to provide maximum chances of success. The methods of administering interventions are just as important as when and where these interventions are implemented. It is common to see broad recommendations to change policies, improve the quality of jobs, and reduce poverty, but policymakers need to take into account evidence on how such policies affect the social determinants of health in order to have a more accurate image of the consequences of such changes. Newcomer communities and main stream agencies need to build capacity to address mental health-related needs of newcomer populations, adapt services 
and programs to meet the mental health needs of these groups, and make changes sustainable in order the ensure continuity of the programs. Introducing cultural competence at multiple levels of service delivery is a key feature in accomplishing such social change. "Cultural competence is a set of congruent behaviors, attitudes, and policies that come together in a system, agency or among professionals and enable that system, agency or those professionals to work effectively in cross-cultural situations." (Cross et al., 1989). Principles of competency include inclusiveness, anti-oppression, equity, valuing of cultural differences, and reflection of diversity.

Since the social determinants of health play a huge role in the mental health of individuals, they must also be a key component in any public policy meant to address mental health and reduce inequities. An analysis paper by Carey and Crammond (2015) identified certain powerful system intervention points that could leverage the maximum benefits of changes created in the system. They call for "adaptive" or "learning" policies, where relevant information reaches the right places in an efficient manner, and creates feedback loops for balance in the system, ensuring that changes occur based on the information collected. For example, since a significant portion of immigrants face language-related barriers, providing more language training and bridging programs (that help transition internationally trained professionals to match their credentials with work experience) early on can help limit these barriers. The target number of graduates from such training programs can be adjusted based on the number of immigrants entering a province, or on another scale that is relevant. Such built-in policy adjustments will be able to speed up the processing time necessary for responding to changing situations. The following section focuses on some of the ways in which barriers can be tackled. Peterborough specific examples highlight some of the changes already being undertaken by the city to reduce disparities, while others focus on areas of potential development. 


\section{Settlement SeRVices}

Settlement services are excellent resources for newcomers to Canada. Settlement services are usually non-profit organizations that provide outreach programs and supports designed to help newcomers make necessary adjustments for a successful integration (Shields, Drolet, \& Valenzuela, 2016). The goal of settlement is for every immigrant to have the freedom of choice to fully participate in their community (or not), and experience no systemic barriers in doing so (Shields, Drole, \& Valenzuela, 2016).

The New Canadian Centre (NCC), as previously mentioned, is the only settlement service agency in the Peterborough area and it offers a variety of services to help in the integration process of their clients. The NCC serves over 1000 clients a year from Peterborough and its surrounding areas of Cobourg, Port Hope, Lakefield, Lindsey, and Omemee (Karn, 2016; Robinson et al., 2010). Robinson et al. found that the NCC was not just a service provider, but also a social hub that provided professional and personal networking opportunities, informal counselling, and a break from the isolation faced by many immigrants after arrival to a new place. Some specific examples of services provided by the NCC include community orientation, employment counselling, computer classes, English language training, informational workshops, and other general informal counselling (Robinson et al., 2010). Refugee resettlement support is a new focus for the NCC that is geared strongly towards helping in the settlement process of new Syrian refugees entering Peterborough.

The NCC, like many other non-profit organizations, are often limited in the work they are able to do due to the limited funding opportunities available to them. With only 11 full-time employees, it is a challenge to find time to help every new client, resulting in the need to prioritize requests (Robinson et al., 2010). Along with the usual services, the NCC has also been 
providing additional refugee related support to sponsoring groups and families since early 2016, without access to additional funding. Guaranteed funding for the many programs offered by the NCC will go a long way to ensuring that they are able to continue to provide high quality support to all the newcomers of Peterborough and surrounding regions.

\section{LANGUAGE/INTERPRETER SERVICES}

The main role of an interpreter is to bridge the language barrier between individuals speaking in different languages so as to promote mutual understanding of facts in order to create seamless communication. Interpreting services may be provided by individuals with differing levels of training. Family members or friends of the patients are considered informal or ad hoc interpreters and usually have no formal training in either health or interpretation. This may also include bilingual health centre staff, not directly involved in providing care. Formal interpreters typically have a background in interpretation, sometimes possessing cultural and/or medical competencies, and may provide services face-to-face or over the telephone (PASS, 2008).

Using trained formal interpreters in the health sector provides many benefits. These benefits range from improving patient and provider satisfaction, maintaining ethics of informed consent and confidentiality, improving treatment comprehension and adherence, enhancing health education, increasing efficacy of time during consultations, improving access to care, reducing risks of medical errors, and reducing costs (PASS, 2008). To date, Peterborough lacks professional and informal interpreter services. There is also no information on the number of requests for interpreter services on an annual basis, or the languages mostly requested. As a step in the right direction, Trent University, in Peterborough, is currently developing a continuing education program that will teach Arabic for Beginners (Trent University, 2016). This is an excellent example of change which allows the receiving community to become ready to provide 
interpreter support to incoming immigrants and refugees and thereby reduce language barriers to accessing services. However, there is much more that needs to be done in this area. Ability of care providers to access quick and affordable interpreter services is sure to increase the quality of care received by their clients.

\section{INCOME INEQUALITY}

Employment gives people income security, a sense of identity, and helps people come in contact with like-minded individuals with whom they can create social bonds. Reducing income inequality is a major step towards decreasing barriers to experiencing gainful employment for both immigrants and the general population. Progressive taxation combined with increasing minimum wage, access to affordable high-quality child care services, improved access to affordable healthy foods, and providing assistance to those unable to work have all been recommended as steps needed to move in the right direction (Mikkonen \& Raphael, 2010).

There is a fundamental imbalance of power that exists between employers and employees (Workers' Action Centre, 2005). There is very little active enforcement of the Canada Labour Code in workplaces, leaving workers vulnerable to substandard working conditions, if the employer chooses (Workers' Action Centre, 2005). An estimated one in three Ontario employers is currently thought to be violating provincial employment standards (Worker's Action Centre, 2005). It is important to reduce this power inequality and ensure that employees are not being exploited. Due to lack of knowledge of rights, newcomers are usually reluctant to report abuse by their employers, especially those in Canada who are living and working in precarious positions under temporary work visas. There needs to be public education around such matters, whistleblower protection laws, and employment security. Such information also needs to be accessible and easy to understand for non-English speakers. 
It is important to help immigrants flourish in their new environments and make the best use of their skills. Assisting immigrants to upgrade their qualifications or reach Canadian standards in their field will help alleviate some mental stress and contribute to the improvement of employment opportunities. Peterborough is home to three major post-secondary educational institutions: Trent University, Sir Sanford Fleming College, and Trillium College. The aviation program campus for Seneca College is also housed in Peterborough. Fleming College boasts over 500 international students while Trent University has an enrollment of over 600 international students (Karn, 2016). These institutions are capable of providing bridging programs and skills development courses that can assist newcomers in entering the work environment quickly.

It is clear from the study conducted by Robinson et al. (2010) that employment is a major concern for newcomers to Peterborough. They found that one of the most common requests received by the NCC (New Canadian Centre) annually was for assistance with resume writing and interview preparation, job search assistance, and networking with employers. However, they found that job search assistance was not always successful, potentially due to the fact that it is often difficult to find employment in Peterborough, not just for newcomers, but for the broader community as a whole. This trend is potentially changing. The unemployment rate of Peterborough for November 2016 was $4.8 \%$, compared to a $6.3 \%$ unemployment rate of Ontario (Statistics Canada, 2016b). In order to help newcomers in their journey to economic freedom, Peterborough Partnership Council on Immigrant Integration (PPCII) was started in 2008 to provide community leadership and encourage meaningful "economic, social and cultural integration of newcomers" in order to ensure a prosperous and inclusive community for everyone (PPCII, 2016). The partnership includes 60 local organizations working together to tackle issues 
associated with immigrant integration. Other non-profit organizations in Peterborough like the Peterborough Economic Development (PED) and the Greater Peterborough Innovation Cluster (GPIC) constantly work towards economic growth of the community and help in the innovation and development of new businesses. Thanks to such organizations, Peterborough enjoys one of the highest rates of immigrant entrepreneurship in Canada (36\%), which has been linked to stronger economies (Vital Signs, 2016). The recently announced Trent Research and Innovation Park will see the development of 130 acres of university land transformed into the hub of sustainable research and encourage further economic development for the city (Rellinger, 2016).

\section{KNOWLEDGE BROKERING}

A knowledge broker is "an individual who engages in a two-way communication with other individuals - acknowledging the value of other beliefs and knowledge systems and the importance of facilitating a bridging of approaches and beliefs". (Pottie et al., 2007). The only way to improve the healthcare system and develop effective policies is by engaging in multiple levels of knowledge brokering whereby researchers continuously monitor changes in population health, disseminate the information to policy makers, and recognize that both are responsible for the uptake and implementation of this knowledge into practice (Pottie et al., 2007). On the other hand, knowledge brokering also needs to occur on a cross-cultural basis, where communication between the healthcare provider and the immigrant patient is improved by understanding the cultural and historical context of the patient (Pottie et al., 2007). Knowledge brokering gives the opportunity for immigrant communities to build relationships with their care providers, flourish in a preventative medicine setting, and fills patients with a sense of trust and empowerment (Pottie et al., 2007). 
Community education is of paramount importance when it comes to raising awareness of mental illness symptoms and treatment options in order to increase utilization of mental health services. When such awareness programs are designed and presented by a particular ethnic group and are culturally sensitive, they have the potential to impact a large number of people (Park, 2013). For example, the Heart and Stroke Foundation in Toronto does a great job of delivering health messaging through advertisements that include multiple ethnicities so that the information is relatable. Having ethnocentric messaging present in the community helps increase awareness and exchange of diverse ideas. Cultural festivals are also good at increasing knowledge of services available to ethnic communities. Examples of such events in Peterborough, mentioned below, create a conversation around understanding and acceptance. Bringing normalcy to seeking help from service providers will increase utilization of services by the targeted population.

\section{CONTINUITY \& COMMUNITY}

With the introduction of new budgets and politicians, there is usually an influx of new programs created to help IRER (immigrants, refugees, ethnocultural, and racialized) groups. While ideal for short term, many of these programs lose funding after the first few years of implementation, usually without a thorough evaluation of program effectiveness. After this point, organizations offering these programs struggle to find funding to keep the programs alive, or simply stop providing them. Such an issue creates a discontinuity in services. It would perhaps be more cost-effective and efficient if such programs were incorporated into the mainstream services. This way, the programs can be regularly evaluated for effectiveness and become part of the regular operating costs, leaving organizers to focus on service delivery rather than fundraising. Incorporating programs into the mainstream could, however, backfire. If the 
program is part of the mainstream, the services provided have to be tailored to the general population, losing the culturally-relevant component. This may further discourage immigrants from accessing such services. Making such services culturally competent will avoid the alienation of newcomers when accessing the mainstream services.

Peterborough demonstrates a very positive way of providing opportunities that can be accessed by the general population as well as specific niche populations. Multicultural Canada Day festival, an event hosted by the NCC (new Canadian Centre) every year, is one of the biggest Canada Day celebrations in Peterborough that brings together a variety of international food and craft vendors and stage performers to celebrate the rich cultural diversity of the area. Another event is the 'Taste of Downtown' that is hosted by the Peterborough Downtown Business Improvement Area, during which the main downtown streets are blocked off to traffic and vendors take to the streets providing various cuisines and multicultural performances. These events are not services that are being offered, yet, they bring the community together, help the mainstream population uncover the diversity of the city, and increase a sense of belonging to the community. Peterborough has also shown excellent community support during the Syrian refugee crisis with over 40 different public sponsorship groups in the Peterborough and surrounding counties, leaving very few people and organizations uninvolved in the process of assisting with integration and settlement of these newcomers. As more people become aware of the barriers that the newcomers were facing, there is a much larger interest in making adjustments in the community to help negate those barriers. 


\section{AREAS OF FURTHER RESEARCH}

Very little research currently exists regarding the variability in the level and quality of treatment available to Canadian citizens versus immigrants and refugees within Canada. This data is even more limited when looking for statistics specific to a certain region of the country, such as Peterborough. To understand how immigrants are faring in our mental health and addictions system, information needs to be collected on rates of participation and utilization of these services, and how such utilization impacts treatment outcomes.

The study of immigrant mental health is relatively recent, and multiple areas require further understanding. Unfortunately, many articles dealing with immigrant health tend to look at immigrants as a single homogenous group rather than a diverse population, and the results of such studies may lead to policy changes that do not necessarily reflect the needs of any single group in particular. Research also tends to be limited to adult populations, ignoring the appropriate service needs of immigrant youth, as well as the elderly (Hansson et al., 2010). It is thus important to keep such limitations in mind when one embarks on the journey of fact finding.

A significant gap in the literature currently involves examining the differences between immigrants with different immigration statuses within the country. Campbell, Klei, Hodges, Fisman, and Kitto (2014) identified some unique challenges that only undocumented immigrants experience that may have a huge influence on their quality of health, such as their lack of health insurance, their fear of authority and being deported, and the precarious situation they may have faced in their past and are facing in their current society. Such factors play a crucial role in how individuals interact with the healthcare system and what quality of care they receive. 
Immigrant and refugee women are another class of immigrants that deserve a more thorough examination. They have unique mental healthcare needs, and more research is required to identify these needs and how best to meet them (Donnelly et al., 2011; Mahony \& Donnelly, 2010). How women interact with and negotiate their Canadian and home society, and how it influences their practices, can impact not only their own health, but the health of their children and the entire household.

There is a growing need to examine the additional barriers faced by the LGBTQ immigrant population. This group experiences multiple levels of vulnerability and stigma, and further research is needed to understand their unique challenges and mental health needs.

In addition to studying specific population groups, readers may be interested in contemplating and researching other questions and topics of interest. Most papers on healthcare services call governments to action to fashion change in society. Is it the responsibility of the federal, provincial, or municipal governments to resolve the mental health needs of the immigrant populations, or should this be an individual endeavor? Do the current policies reflect what is actually being practiced and offered in the healthcare sector? Is there a difference in the level of life satisfaction that immigrants experience compared to the Canadian population, and what factors influence the level of satisfaction? Do Canadians feel a sense of entitlement when it comes to healthcare services, and treat immigrants as a burden on the system? These are all difficult questions to answer, yet important to keep in mind.

\section{CONCLUSION}

It is imperative that research in the areas discussed in this paper continues to progress. In particular, it is important to improve the collection of disaggregated data on the race or ethnicity 
of the population so we can more accurately examine the effects of individual population-wide programs. Canada has taken many positive steps by funding programs such as the Mental Health Strategy, which encourages research aimed at improving the mental health and well-being of Canadians. It is also important to tweak the data collection on a national level so we can measure the success of such programs. Rarely do forms filled out in the office of a family physician ask about the ethnic origins of a patient. If they did, we would be better able to predict help-seeking behaviours and mental health utilization practices based on such demographics. Only when more in-depth information becomes available will we have clearer ideas of health disparities and inequities, and be more able to address changes to eliminate those inequities. All lawmakers and policy makers need to adopt a social equity framework through which all new initiatives need to pass and commit to understanding the barriers that all marginalized groups face every day. It is possible to enact positive and productive changes, using the determinants of health, which will provide good healthy living conditions for everyone in Canada.

"What is required goes beyond mere tolerance or sympathy or sensitivity... True cultural sensitivity is something far more rigorous, and even more intellectual than that. It implies a readiness to study and to learn across cultural barriers, an ability to see others as they see themselves" (His Highness the Aga Khan, 2008). It is this ability to understand others that needs to be incorporated into all levels of services provided to individuals all over the world. In order to provide equitable treatment to all those seeking mental healthcare services, first, we need to understand their lives, their cultures, their identities. We need to understand their barriers and challenges. We then need to provide services based on those characteristics in the most responsive way possible. It is the responsibility of the community and the government to play a role in preventing mental health and addiction problems, address the stigma around such issues, 
provide information and education about support services available, and reach out to the ethnic minorities in the communities to build and maintain lasting partnerships that will remove barriers.

It is not enough to claim that Canada is a mosaic of multiculturalism and accept that Canada is home to many cultures and races. It is important to first acknowledge that discrimination and racism exist, even in Canada, and then develop education and awareness programs that advocate for change in the attitudes and treatment of our immigrant population. Likewise, it is important to balance our expectations and accept that every single individual plays a vital role in the progress of this nation and provide them the means to succeed. Only then will Canada be able to fulfill the promises it made in the Canada Health Act and the Multicultural Act, to treat everyone in Canada with dignity and provide services without barriers. 


\section{APPENDIX/ACRONYMS}

CAMH: Centre for Addiction and Mental Health (http://www.camh.ca/)

CCDSS: Canadian Chronic Disease Surveillance System

CIC: Citizenship and Immigration Canada (currently: IRCC: Immigration, Refugees and Citizenship Canada) (www.cic.gc.ca)

GBD: Global Burden of Disease (http://www.who.int/healthinfo/global_burden_disease/gbd/en/)

IRER: Immigrants, Refugees, Ethnocultural, and Racialized groups. This term encompasses newcomers to Canada (temporary residents, permanent residents, or refugees), visible minorities, ethnic minorities, second generation Canadians, and anyone who self-identify as belonging to an ethnic community that is traditionally considered non-Canadian.

MRP: Major Research Paper

NCC: New Canadian Centre (www.nccpeterborough.ca)

NHS: National Household Survey

OHIP: Ontario Health Insurance Plan (http://www.health.gov.on.ca/en/public/programs/ohip/)

PASS: Partners for Applied Social Sciences

PHAC: Public Health Agency of Canada (http://www.phac-aspc.gc.ca/)

PPCII: Peterborough Partnership Council on Immigrant Integration

SAMHSA: Substance Abuse and Mental Health Services Administration (https://www.samhsa.gov/) 
WHO: World Health Organization (http://www.who.int) 


\section{REFERENCES}

Albert, P. R. (2015). Why is depression more prevalent in women? Journal of Psychiatry and Neuroscience, 40(4), 219-221. Retrieved from:

https://www.ncbi.nlm.nih.gov/pmc/articles/PMC4478054/.

American Psychiatric Association (Ed.). (1994). Diagnostic and statistical manual of mental disorders (4th ed.). Washington, DC.

American Psychological Association [APA] (2015). Understanding chronic stress. Retrieved from http://www.apa.org/helpcenter/understanding-chronic-stress.aspx.

Amri, S., and Bemak, F. (2013). Mental health help-seeking behaviors of Muslim immigrants in the United States: Overcoming social stigma and cultural mistrust. Journal of Muslim Mental Health, 7(1), 43-63. Retrieved from: http://quod.lib.umich.edu/cgi/p/pod/dodidx/mental-health-help-seeking-behaviors-of-muslimimmigrants.pdf?c=jmmh;idno=10381607.0007.104.

Andersen, R. M. (1995, March). Revisiting the Behavioral Model and access to medical care: Does it matter? Journal of Health and Social Behavior, 36(1), 1-10.

Barron, D. S., Holterman, C., Shipster, P., Batson, S., and Alam, M. (2010). Seen but not heard - ethnic minorities' views of primary health care interpreting provision: A focus group study. Primary Health Care Research and Development, 11, 132-141.

Batalova, J. and Fix, M. (2010). A profile of limited English proficient adult immigrants. Peabody Journal of Education, 85, 511-534. 
Bauer, H. M., Rodriguez, M. A., Quiroga, S. S., and Flores-Ortiz, Y. Z. (2000). Barriers to health care for abused Latina and Asian immigrant women. Journal of Health Care for the Poor and Underserved, 11, 33-44.

Baysu, G., Celeste, L., Brown, R., Verschueren, K., and Phalet, K. (2016). Minority adolescents in ethnically diverse schools: Perceptions of equal treatment buffer threat effects. Child Development, 87(5), 1352-1366.

Beiser, M. (2005). The health of immigrants and refugees in Canada. Immigrant and Refugee Health, 96 (supp 2), s30-s44.

Beiser, M. and Hou, F. (2001). Language acquisition, unemployment and depressive disorder among South East Asian refugees: A 10 year study. Social Sciences and Medicine, 53, 1321-1334.

Bowen, S. (2001). Language barriers in access to health care. Ottawa: Health Canada.

Brisset, C., Leanza, Y., Rosenburg, E., Vissandjee, B., Kirmayer, L., Muckle, G., Xenocostas, S., and Laforce, H. (2014). Language barriers in mental health care: A survey of primary care practitioners. Journal of Immigrant Minority Health, 16:1238-1246.

Campbell, R. M., Klei, A. G., Hodges, B. D., Fisman, D., and Kitto, S. (2014). A comparison of health access between permanent residents, undocumented immigrants and refugee claimants in Toronto, Canada. Journal of Immigrant Minority Health, 16: 165-176.

Canadian Human Rights Commission [CHRC]. (2013, January 9). What is discrimination? Retrieved from: http://www.chrc-ccdp.gc.ca/eng/content/what-discrimination. 
Canadian Medical Association [CMA] - \& The College of Family Physicians of Canada. (2009, December). The wait starts here. The primary care wait time partnership. Final Report. Retrieved from: https://www.cma.ca/Assets/assets-library/document/en/advocacy/policyresearch/CMA_Policy_The_Wait_Starts_Here_Final_Report_of_the_Primary_Care_Wait_Time _Partnership_PD10-01-e.pdf.

Canadian Task Force on Mental Health Issues Affecting Immigrants and Refugees. (1988). After the door has been opened: Mental health issues affecting immigrants and refugees. Ottawa: Minister of Supply and Services Canada.

Carey, G. and Crammond, B. (2015). Systems change for the social determinants of health. BMC Public Health, 15:662.

Carroll, J. K. (2004). Murug, waali, and gini: Expressions of distress in refugees from Somalia. Primary Care Companion to the Journal of Clinical Psychiatry, 6, 119-125.

Chiu, M., Lebenbaum, M., Newman, A. M., Zaheer, J., and Kurdyak, P. (2016). Ethnic differences in mental illness severity: A population based study of Chinese and South Asian patients in Ontario, Canada. Journal of Clinical Psychiatry, Aug electronic publication.

Chowdhury, N. L. and Fowler, K. (May 2011). Predictors of mental health in Canadian immigrants: Exploring the impact of social environment on chronic distress. Paper presented at 35th Annual APICS Psychology Conference. Dalhousie: Halifax.

Chui, T. and Maheux, H. (2011, July). Visible minority women. Statistics Canada. Ottawa. Retrieved from: http://www.statcan.gc.ca/pub/89-503-x/2010001/article/11527-eng.pdf. 
Citizenship and Immigration Canada [CIC]. (2016). Applying for permanent residence from within Canada: Spouse or common - law partner in Canada class (IMM 5289). Retrieved from: http://www.cic.gc.ca/english/information/applications/guides/5289ETOC.asp.

City of Peterborough (2016, February 10). About Peterborough. Retrieved from: http://www.peterborough.ca/Visiting/About_Peterborough.htm.

College of Physicians and Surgeons. (2016). All doctors search. Retrieved from: http://www.cpso.on.ca/public-register/all-doctors-search.

Cook, E. P. (1990). Gender and psychological distress. Journal of Counseling \& Development, 68, 371-375.

Cross, T. L., Bazron, B. J., Dennis, K. W., and Isaacs, M. R. (1989). Towards a culturally competent system of care: A monograph on effective services for minority children who are severely emotionally disturbed. Washington. Retrieved from: http://files.eric.ed.gov/fulltext/ED330171.pdf.

David, E. J. R. (2010). Cultural mistrust and mental health help-seeking attitudes among Filipino Americans. Asian American Journal of Psychology, 1(1), 57-66.

Donnelly, T. T., Hwang, J. J., Este, D., Ewashen, C., Adair, C., and Clinton, M. (2011). If I Was Going to Kill Myself, I Wouldn’t Be Calling You. I am Asking for Help: Challenges Influencing Immigrant and Refugee Women's Mental Health. Issues in Mental Health Nursing, 32:279-290. 
Global burden of Disease. (2010). GBD Profile: Canada. Retrieved from:

https://www.healthdata.org/sites/default/files/files/country_profiles/GBD/ihme_gbd_country_rep ort_canada.pdf.

Goh, J., Pfeffer, J., and Zenio S. A. (2015). The relationship between workplace stressors and mortality and health costs in the United States. Management Science, Articles in Advance, 121.

Gordon, R. (1987). An operational classification of disease prevention. In: Steinberg JA, Silverman MM, eds. Prevention of Mental Disorders. Rockville, MD, Department of Health and Human Services, 20-26.

Hagerty, B. M., Williams, R. A., Coyne, J. C., and Early, M. R. (1996). Sense of belonging and indicators of social and psychological functioning. Archives of Psychiatric Nursing, 10(4), 235-244.

Hansson, E., Tuck, A., Lurie, S., McKenzie, K. for the Task Group of the Services Systems Advisory Committee, Mental Health Commission of Canada. (2010). Improving mental health services for immigrant, refugee, ethno-cultural and racialized groups: Issues and options for service improvement. Retrieved from: https://www.mentalhealthcommission.ca/English/system/files/private/Diversity_Issues_Options Report_ENG_0.pdf.

Harrell, S. P. (2000). A multidimensional conceptualization of racism-related stress: Implications for the well-being of people of color. American Journal of Orthophychiatry, $70(1): 42-57$. 
Hassard, J., Teoh, K., Cox, T., Dewe, P., Cosmar, M., Grundler, R., Cosemans, B., and Van den Broek, K. (2014). Calculating the cost of work-related stress and psychosocial risks. European Agency for Safety and Health at Work. Retrieved from:

https://osha.europa.eu/en/tools-and-publications/publications/literature_reviews/calculating-thecost-of-work-related-stress-and-psychosocial-risks.

His Highness the Aga Khan. (2008, April 18). Speech at annual meeting of the International Baccalaureate. Atlanta: Georgia. Retrieved from: http://www.akdn.org/speech/hishighness-aga-khan/annual-meeting-international-baccalaureate.

Karn, A. (2016). Peterborough Possibilities: A refined perspective on success in Peterborough \& the Kawarthas. Peterborough Possibilities, Fall 2016: MyKawartha.

Keung, N. (2014, June 10). Toronto forges ahead with "sanctuary city" plan. Toronto Star. Retrieved from:

https://www.thestar.com/news/city_hall/2014/06/10/toronto_forges_ahead_with_sanctuary_city_ plan.html.

Kirmayer, L. J., Weinfel, M., Burgos, G., Galbaud du Fort, G., Lasry, J., and Young, A. (2007). Use of health care services for psychological distress by immigrants in an urban multicultural milieu. The Canadian Journal of Psychiatry, 52(5), 295-304.

Kovach, J. (2016, September 16). 180 Syrian refugees expected in Peterborough by year's end; more to come in 2017. The Peterborough Examiner. Retrieved from: http://www.thepeterboroughexaminer.com/2016/09/16/180-syrian-refugees-expected-inpeterborough-by-years-end-more-to-come-in-2017. 
Leong, F. T. and Lau, A. S. (2001). Barriers to providing effective mental health services to Asian Americans. Mental Health Services Research, 3(4), 201-214.

Luther, R. (2007). Access and equity in Ottawa: A snapshot of social service issues, institutional responses and remaining challenges regarding culture, race and language. Our Diverse Cities, Ontario, Number 4, 39-43.

Madianos, M. G., Zartaloudi, A., Alevizopoulos, G., and Katostaras, T. (2011). Attitudes toward help-seeking and duration of untreated mental disorders in sectorized Athens area of Greece. Community Mental Health Journal, 47(5), 583-593.

Mahony, J. and Donnelly, T. (2010). Immigrant and refugee women's post-partum depression help-seeking experiences and access to care: a review and analysis of the literature. Journal of Psychiatric and Mental Health Nursing, 17, 917-928.

Mayhew, M. (2016, January). How culture influences health. Caring for kids new to Canada. Retrieved from: http://www.kidsnewtocanada.ca/culture/influence.

McCallum, C., and McLaren, S. (2011). Sense of belonging and depressive symptoms among GLB adolescents. Journal of Homosexuality, 58, 83-96.

Mental Health Commission of Canada. (2013). Making the case for investing in mental health in Canada. Retrieved from: http://strategy.mentalhealthcommission.ca/wpcontent/uploads/2013/03/Case_for_Investment_Mar2013_ENG.pdf.

Mental Health Commission of Canada. (2012). Changing directions, changing lives: The mental health strategy for Canada. Calgary, AB: Author. 
Mikkonen, J., and Raphael, D. (2010). Social Determinants of Health: The Canadian Facts. Toronto: York University School of Health Policy and Management. Retrieved from: http://www.thecanadianfacts.org/the_canadian_facts.pdf.

Ministry of Justice. (2016a). Canada Health Act, R.S.C., 1985, c. C-6. Consolidation. Retrieved from: http://laws-lois.justice.gc.ca/PDF/C-6.pdf.

Ministry of Justice. (2016b). Canadian Multiculturalism Act, R.S.C., 1985, c. 24 (4 $4^{\text {th }}$ Supp.). Consolidation. Retrieved from: http://laws-lois.justice.gc.ca/PDF/C-18.7.pdf.

National Household Survey [NHS] (2016). NHS focus on geography series, Peterborough, City. Retrieved from: http://www12.statcan.gc.ca/nhs-enm/2011/as-sa/fogsspg/Pages/FOG.cfm?lang=E\&level=4\&GeoCode=3515014\#ethno1.

National Household Survey [NHS] (2011). Immigration and ethnological diversity in Canada. Statistics Canada. Retrieved from: http://www12.statcan.gc.ca/nhs-enm/2011/as-sa/99010-x/99-010-x2011001-eng.cfm.

New Canadian Centre [NCC]. (2016). Refugee Resettlement Support. How you can support refugees. Retrieved from: http://www.nccpeterborough.ca/?page_id=10560.

No one is illegal - Toronto. (2016). Vision, demands, organizing pillars. Retrieved from: http://toronto.nooneisillegal.org/demands.

Nolan-Hoeksema, S. and Rector, N. A. (2008). Abnormal Psychology (Canadian Ed.). Toronto: McGraw-Hill Ryerson. 
Nordt, C., Warnke, I., Seifritz, E., and Kawohl, W. (2015). Modelling suicide and unemployment: a longitudinal analysis covering 63 countries, 2000-11. Lancet Psychiatry, 2: $239-45$.

On the Coast. (2016, March 7). Walk-in clinics getting slammed by doctor shortage, owner says. CBC News. Retrieved from: http://www.cbc.ca/news/canada/british-columbia/walkin-clinics-patient-caps-1.3480377.

Ontario.ca (2016). Teeth cleaning, check-ups, and dental treatment for kids. Retrieved from: https://www.ontario.ca/page/get-dental-care.

Ontario Health Insurance Plan [OHIP]. (2015, May). Ministry programs, Ontario Health Insurance Plan, Questions and Answers. Retrieved from: http://www.health.gov.on.ca/en/public/programs/ohip/ohipfaq_mn.aspx.

Park, S-Y., Cho, S., Park, Y., Bernstein, K. S., and Shin, J. K. (2013). Factors associated with mental health services utilization among Korean American immigrants. Community Mental Health Journals, 49(6): 765-773.

PASS International v.z.w. - Partners for Applied Social Sciences. (2008 March) Is the use of interpreters in medical consultations justified? A critical review of the literature. Retrieved from: http://www.wrha.mb.ca/staff/language/files/Article-MedicalConsult.pdf.

Pearson, C., Janz, T., and Ali, J. (2013, September 18). Mental and substance use disorders in Canada. Statistics Canada: Health at a Glance. Cat No. 82-624-X. Available at: http://www.statcan.gc.ca/pub/82-624-x/2013001/article/11855-eng.pdf. 
Peterborough Partnership Council on Immigrant Integration [PPCII]. (Website). Mandate, history and governance. Retrieved from: http://www.ppcii.ca/mandate-historygovernance/.

Picot, G. and Hou, F. (2014, December 15). Immigration, low income and income inequality in Canada: What's new in the 2000s? Statistics Canada: Analytical Studies Branch Research Paper Series. Available at: http://www.statcan.gc.ca/pub/11f0019m/11f0019m2014364-eng.pdf.

Pilisuk, M., and Parks, S. H. (1980). Structural dimensions of social support groups. The Journal of Psychology, 106(2), 157-177.

Pottie, K., Ortiz, L., and Kuile, A. T. for the Canadian Initiative to Optimize Preventive Services for Immigrants (CIOPSI) Team. (2007). Preparing for diversity: Improving preventive health care for immigrants. Our Diverse Cities, Ontario, Number 4, 59-63.

Public Health Agency of Canada [PHAC]. (2015). Report from the Canadian Chronic Disease Surveillance System: Mental illness in Canada, 2015. Retrieved from: http://healthycanadians.gc.ca/publications/diseases-conditions-maladies-affections/mentalillness-2015-maladies-mentales/alt/mental-illness-2015-maladies-mentales-eng.pdf.

Rellinger, P. (2016, February 24). Development of lands at Trent University will be “transformational". Kawartha Now. Retrieved from: http://kawarthanow.com/2016/02/24/trentuniversity-lands-plan/.

Riley, D., and Eckenrode, J. (1986). Social ties: Subgroup differences in costs and benefits. Journal of Personality and Social Psychology, 51(4), 770-778. 
Robinson, M., Taft, M., and Turley, R. (2010). Evaluation of settlement services, for the New Canadian Centre Peterborough. Trent Centre for Community Based Education. Retrieved from: http://trentcentre.ca/documents/public/4057FinalReport.pdf.

Shields, J., Drolet, J., and Valenzuela, K. (2016, February). Immigrant settlement and integration services and the role of nonprofit service providers: A cross-national perspective on trends, issues and evidence. RCIS working paper no. 2016/1. Retrieved from: http://www.ryerson.ca/content/dam/rcis/documents/RCIS\%20WP\%202016_01\%20Shields\%20et \%20al\%20final.pdf.

Spitzer, D. (2011, February). Is migrating to Canada bad for your health? Paper presented at Memorial University of Newfoundland. St. John's: Newfoundland.

Statistics Canada. (2016a). Focus on Geography Series, 2011 Census, Census metropolitan area of Peterborough, Ontario. Retrieved from: http://www12.statcan.gc.ca/censusrecensement/2011/as-sa/fogs-spg/Facts-cma-eng.cfm?LANG=Eng\&GK=CMA\&GC=529.

Statistics Canada. (2016b). Labour force information: November 6 to 12, 2016. Catalogue no. 71-001-x. Retrieved from: http://www.statcan.gc.ca/pub/71-001-x/71-001x2016011-eng.pdf.

Statistics Canada. (2015). Access to a regular medical doctor, 2014. Retrieved from: http://www.statcan.gc.ca/pub/82-625-x/2015001/article/14177-eng.htm.

Statistics Canada. (2013). Average female and male earnings, and female-to-male earnings ratio, by work activity, 2011 constant dollars, annual, CANSIM. Table 202-0102. Retrieved from: http://www5.statcan.gc.ca/cansim/a26?lang=eng\&id=2020102. 
Stewart, M., Anderson, J., Beiser, M., Mwakarimba, E., Neufeld, A., Simich, L., et al. (2008). Multicultural meanings of social support among immigrants and refugees. International Migration, 46(3), 123-159.

Substance Abuse and Mental Health Services Administration [SAMHSA]. (2015). Racial/ethnic differences in mental health service use among adults. HHS publications no. SMA15-4906. Rockville, MD: Substance Abuse and Mental Health Services Administration. Retrieved from: http://store.samhsa.gov/shin/content/SMA15-4906/SMA15-4906.pdf.

Tajfel, H. and Turner, J. C. (1986). The social identity theory of intergroup behaviour. In S. Worchel and W. G. Austin (Eds.), Psychology of intergroup relations (2nd ed., pp. 7-24). Chicago: Nelson-Hall.

Takeuchi, D. T., Alegria, M., Jackson, J. S., and Williams, D. R. (2007). Immigration and mental health: Diverse findings in Asian, Black, and Latino populations. (Editorial). American Journal of Public Health, 1, 11-12.

Takeuchi, D. T., Chung, R. C., Lin, K., Shen, H., Kurasaki, K., Chun, C., et al. (1998). Lifetime and twelve-month prevalence rates of major depressive episodes and dysthymia among Chinese Americans in Los Angeles. American Journal of Psychiatry, 155(10), 1407-1414.

Talbot, Y., Fuller-Thomson, E., Tudiver, F., Habib, Y., and McIsaac, W. J. (2001). Canadians without regular medical doctors. Who are they? Canadian Family Physician, 47, 5864. 
Tiwari, S., K., and Wang, J. L. (2008). Ethnic differences in mental health service use among White, Chinese, South Asian and South East Asian populations living in Canada. Social Psychiatry and Psychiatric Epidemiology, 43, 866-871.

Trent University. (2016). Continuing Education: Arabic for Beginners. Retrieved from: https://www.trentu.ca/continuingeducation/courses/arabic-beginners.

Vineberg, R. (2014, April 21). After 40 years, immigrant settlement program needs an overhaul. The Globe and Mail. Retrieved from: http://www.theglobeandmail.com/opinion/after40-years-immigrant-settlement-program-needs-an-overhaul/article18075025/.

Vital Signs. (2016). Community Foundation of Greater Peterborough. Retrieved from: http://cfgp.ca/downloads/CFGP_VitalSigns_WEB.pdf.

Wareham, S., Fowler, K., and Pike, A. (2007). Determinants of depression severity and duration in Canadian adults: The moderating effects of gender and social support. Journal of Applied Social Psychology, 37(12), 2951-2979.

Wild, T. C., Wolfe, J., Wang, J., and Ohinmaa, A. (2014, February). Gap analysis of public mental health and addictions programs (GAP-MAP) final report. University of Alberta: School of Public Health. Retrieved from: http://www.health.alberta.ca/documents/GAP-MAPReport-2014.pdf.

Wilkins, R. (2007). Mortality by Neighbourhood Income in Urban Canada from 1971 to 2001. HAMG Seminar, 16 January 2007. Ottawa: Statistics Canada. 
Workers' Action Centre. (2005, October). Modernizing part 3 of the Canada Labour Code. Submission to the Federal Labour Standards Review. Retrieved from: http://www.workersactioncentre.org/wp-content/uploads/2011/12/pb_Modernizing_eng.pdf.

World Health Organization [WHO] (2014, August). Strengthening mental health promotion (Fact Sheet no.220). Retrieved from:

http://www.who.int/mediacentre/factsheets/fs220/en/.

World Health Organization (WHO) and Calouste Gulbenkian Foundation (CGF). (2014). Social determinants of mental health. Geneva, World Health Organization. Retrieved from: http://apps.who.int/iris/bitstream/10665/112828/1/9789241506809_eng.pdf?ua=1.

World Health Organization (WHO): Department of Mental Health and Substance Dependence. (2002). Prevention and promotion in mental health. Retrieved from: http://www.who.int/mental_health/media/en/545.pdf.

Wright, R. (2006). Social support and health outcomes in a multicultural urban population. Social Work in Health Care, 43(4), 15-28.

U.S. Department of Health and Human Services. (2001). Mental Health: Culture, Race, and Ethnicity—A Supplement to Mental Health: A Report of the Surgeon General. Rockville, MD: U.S. Department of Health and Human Services, Substance Abuse and Mental Health Services Administration, Center for Mental Health Services. Retrieved from: http://www.ncbi.nlm.nih.gov/books/NBK44243/pdf/Bookshelf_NBK44243.pdf. 